A tale of two sectors: why is misallocation higher in services than in manufacturing? Working Papers 2016 



\section{4}

\section{A tale of two sectors: why is misallocation higher in services than in manufacturing?}

Working Papers 2016

Daniel A. Dias | Carlos Robalo Marques | Christine Richmond

August 2016

The analyses, opinions and findings of these papers represent the views of the authors, they are not necessarily those of the Banco de Portugal or the Eurosystem

Please address correspondence to

Banco de Portugal, Economics and Research Department

Av. Almirante Reis 71, 1150-012 Lisboa, Portugal

T+351213130000 | estudos@bportugal.pt

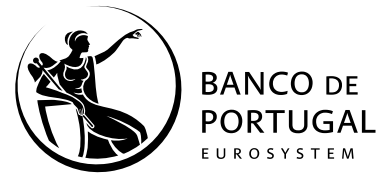

Lisbon, 2016 • www.bportugal.pt 
WORKING PAPERS | Lisbon 2016 • Banco de Portugal Av. Almirante Reis, 71 | 1150-012 Lisboa • www.bportugal.pt • Edition Economics and Research Department • ISBN 978-989-678-469-0 (online) • ISSN 2182-0422 (online) 


\title{
A tale of two sectors: why is misallocation higher in services than in manufacturing?
}

\author{
Daniel A. Dias \\ Board of Governors of the Federal \\ Reserve System
}

\author{
Carlos Robalo Marques \\ Banco de Portugal
}

\section{Christine Richmond}

International Monetary Fund

August 2016

\begin{abstract}
Recent empirical studies document that the level of resource misallocation in the service sector is significantly higher than in the manufacturing sector. We quantify the importance of this difference and study its sources. Conservative estimates for Portugal (2008) show that closing this gap, by reducing misallocation in the service sector to manufacturing levels, would boost aggregate gross output by around 12 percent and aggregate value added by around 31 percent. Differences in the effect and size of productivity shocks explain most of the gap in misallocation between manufacturing and services, while the remainder is explained by differences in firm productivity and age distribution. We interpret these results as stemming mainly from higher output-price rigidity, higher labor adjustment costs and higher informality in the service sector.
\end{abstract}

JEL: D24, O11, O41, O47

Keywords: Misallocation, productivity, firm-level data, structural transformation, Gelbach decomposition.

\footnotetext{
Acknowledgements: We thank the seminar participants at Banco de Portugal, 5th UECE Conference on Economic and Financial Adjustments and 2016 Africa Meeting of the Econometric Society for helpful comments and suggestions. The analyses, opinions and findings of this paper represent the views of the authors, which are not necessarily those of Banco de Portugal, the Eurosystem, the IMF Executive Board, or IMF management, the Board of Governors of the Federal Reserve System or of any other person associated with the Federal Reserve System.

E-mail: daniel.dias@frb.gov; cmrmarques@bportugal.pt; crichmond@imf.org
} 


\section{Introduction}

Recent empirical studies document that the level of resource misallocation in the service sector is significantly higher than in the manufacturing sector. In this paper, we quantify the implications for aggregate productivity and aggregate GDP of the "excess misallocation" in the service sector, and investigate to what extent this misallocation gap reflects structural differences between the two sectors.

A now well accepted result in the growth literature is that differences in the degree of allocative efficiency are one reason why countries differ in terms of aggregate total factor productivity (TFP). Most of the empirical studies linking resource misallocation to differences in TFP have been based on data from the manufacturing or agriculture sectors (see, for instance, Hsieh and Klenow (2009), Camacho and Conover (2010), Machicado and Birbuet (2012), Ziebarth (2013), Bellone and Mallen-Pisano (2013), Adamopoulos and Restuccia (2014), Chen and Irarrazabal (2015), Gopinath et al. (2015), Calligaris (2015)). Despite services being the largest sector for most countries, either in terms of value added or in terms of total employment, it was only recently that estimates of misallocation for the service sector became available (see for instance Dias et al. (2016), Garcia-Santana et al. (2015), and Benkovskis (2015) for Portugal, Spain, and Latvia, respectively).

One new result, common to these economy-wide studies, is that the level of estimated efficiency gains in the service sector is significantly higher than in the manufacturing sector. ${ }^{1}$ Estimates obtained in Dias et al. (2016) for Portugal, for the 2004-2011 period, show that resource misallocation is, on average, 24 percentage points (p.p) higher in services than in manufacturing, when evaluated in terms of gross output, or around 40 p.p. higher, when evaluated in terms of value added (see Table 4 in Dias et al. (2016)). Similarly, estimates in Garcia-Santana et al. (2015) for Spain, for the 2001-2007 period, suggest that efficiency gains are around 22 p.p. higher in services than in manufacturing (see Table 2 in Garcia-Santana et al. (2015)), while estimates in Benkovskis (2015) for Latvia, for the 2007-2013 period, allow us to compute an average misallocation gap of around 32 p.p. between the two sectors. Despite not strictly comparable (methodologies and sectoral definitions vary across papers), these numbers show that the level of resource misallocation in the service sector is significantly higher than in the manufacturing sector.

In order to answer our questions regarding the sources of "excess misallocation" in the service sector and its aggregate implications, we use the theoretical framework developed in Hsieh and Klenow (2009), with the threefactor extension presented in Dias et al. (2016).

1. Although not strictly correct, because there is a one-to-one mapping between efficiency (or TFP) gains from reallocation of resources and misallocation, we refer to both interchangeably throughout the paper. 
Using firm-level data for the Portuguese economy, we first show that the misallocation differences between the manufacturing and service sectors have important implications for aggregate TFP and aggregate GDP. We estimate that if the misallocation gap between services and manufacturing were closed (by making the level of misallocation in the service sector be the same as in manufacturing), aggregate gross output (or aggregate TFP) would increase by about 12 percent, while aggregate value added (GDP) would increase by around 31 percent. We next document that the significantly higher level of resource misallocation in the service sector is the result not of a small number of industries with abnormal levels of misallocation, but of a strong regularity: the majority of industries belonging to the manufacturing sector rank among the industries with the lowest misallocation.

Based on regression analysis, we find that the higher levels of allocative inefficiency in the service sector can be fully explained by structural differences between the two sectors. Idiosyncratic productivity shocks, which impact allocative efficiency in the presence of (capital/labor) adjustment costs and/or output-price rigidity, is the most important factor contributing to the misallocation differences between the two sectors. However, the contribution of productivity shocks stems more from the different impacts, than from the difference in the magnitude of the shocks between the two sectors. In particular, the impact of productivity shocks on misallocation is significantly higher in the service sector than in the manufacturing sector. Further analysis of the different distortions suggests that higher output-price rigidity and higher labor adjustment costs may explain why the effect of productivity shocks on misallocation is larger in services than in manufacturing.

The sectoral firm-size structure, proxied by the skewness of the productivity distribution, emerges as the second most important factor to explain the difference in misallocation between the two sectors. Again, the bulk of the contribution of this regressor stems from its higher impact in the service sector. A higher proportion of low productivity firms in the service sector makes the productivity distribution more right-skewed, contributing to a higher level of misallocation in the service sector stemming from size dependent distortions. The higher level of informality in the service sector may explain why the sectoral structure has more of an impact on the level of misallocation in this sector.

Finally, our empirical model suggests that the proportion of young firms also has a bearing on misallocation differences between the two sectors. Young firms emerge as facing higher capital costs than older firms, which we link to the presence of credit constraints imposed by financial institutions on young firms due to a lack of credit history or because of insufficient guarantees. This regressor has two opposite effects on misallocation differences between the two sectors. On the one hand, the higher proportion of young firms in the service sector contributes to increasing the difference in misallocation between the two sectors but, on the other hand, the impact of this regressor is lower in the service sector, which contributes to reducing misallocation differences between 
the two sectors. Overall, its net contribution is negative. This means that in the absence of this effect, the difference in misallocation between the service and the manufacturing sectors would be even higher.

Our findings have important consequences for developing countries and economies undergoing structural transformation. Duarte and Restuccia (2010) demonstrate that differences in productivity in the service and agriculture sectors across countries are one of the main factors behind overall productivity differences between countries. In particular, low productivity in the service sector and lack of catch-up can explain the experiences of productivity slowdown, stagnation, and decline observed across economies. Hsieh and Klenow (2009) show that differences in misallocation in the manufacturing sector are important to understanding the differences of total factor productivity between developed and developing countries. Using data for the manufacturing sector in China and India, the authors conclude that reducing the level of misallocation in these economies to the levels observed in the U.S. economy would increase productivity by $30-50$ percent in China and 40-60 percent in India. However, if a significant difference of allocative efficiency between manufacturing and the service sector, similar to that documented for Portugal, Spain or Latvia, are present in other countries, the importance of resource misallocation to explaining productivity differences between developed and developing countries may even be higher than what the empirical evidence based on data from the manufacturing sector alone would suggest.

By shedding light on the reasons behind the higher level of misallocation in the service sector relative to the manufacturing sector this paper also contributes to the understanding of the policies that may contribute to increasing productivity growth. Boosting competition so as to reduce output price rigidity in the service sector, avoiding size-contingent laws that may contribute to the survival of unproductive firms and reducing barriers to growth by eliminating credit constraints imposed by financial institutions on young firms, are measures that can contribute to reducing within-industry misallocation, especially in the service sector, and thus to increase aggregate TFP and aggregate value added (GDP).

The rest of the paper is structured as follows. Section 2 provides a brief description of the theoretical framework. Section 3 describes the dataset used in the analysis. Section 4 computes misallocation in the manufacturing and service sectors and discusses the aggregate implications of excess misallocation in the service sector. Section 5 reviews the main potential sources of misallocation suggested in the literature, presents the empirical results and discusses their interpretation. Finally, section 6 summarizes the main findings. 


\section{Theoretical framework}

This section summarizes the methodology used to identify the linkage between aggregate productivity and resource misallocation that results from the existence of distortions and frictions affecting the optimal allocation of factors of production at the firm-level. We adopt the framework developed in Hsieh and Klenow $(2009,2011)$, but extend their model to consider a production function with intermediate inputs, as a third factor of production. The model with three factors of production, as well as the derivation of the full set of results is presented elsewhere (see, Dias et al. (2016)), so here we just briefly review the model and summarize the main results needed for our current purposes.

The model assumes an economy with a single final good $Y$ produced by a representative firm in a perfectly competitive market. This firm combines the output $Y_{s}$ of $S$ industries in the economy using a Cobb-Douglas production technology:

$$
Y=\prod_{s=1}^{S}\left(Y_{s}\right)^{\theta_{s}}
$$

with $\sum_{s=1}^{S} \theta_{s}=1$ and $\theta_{s}=\left(P_{s} Y_{s}\right) /(P Y)$, where $P_{s}$ is the price of industry gross output, $Y_{s}$, and $P$ is the price of the final good. At the industry level, gross output $Y_{s}$ is a CES aggregate of $M_{s}$ differentiated products:

$$
Y_{s}=\left[\sum_{i=1}^{M_{s}}\left(Y_{s i}\right)^{\frac{\sigma-1}{\sigma}}\right]^{\frac{\sigma}{\sigma-1}}
$$

where $Y_{s i}$ stands for the gross output of firm $i$ and parameter $\sigma$ measures the elasticity of substitution between varieties of differentiated goods. At the firm level, the gross output for each differentiated product is given by a CobbDouglas production function:

$$
Y_{s i}=A_{s i} K_{s i}^{\alpha_{s}} H_{s i}^{\beta_{s}} Q_{s i}^{1-\alpha_{s}-\beta_{s}}
$$

where $A_{s i}, K_{s i}, H_{s i}$ and $Q_{s i}$, stand for firm $i^{\prime} s$ total factor productivity (TFP), capital stock, labor and intermediate inputs, respectively.

With three factors of production it is possible to separately identify distortions that affect capital, labor and intermediate input prices simultaneously from distortions that affect the marginal product of one of the factors relative to the others. Thus, we introduce three types of distortions, or wedges, in the model: an output distortion, denoted $\tau_{y_{s i}}$, a capital distortion, $\tau_{k_{s i}}$, and a labor distortion, $\tau_{h_{s i}}$, that take the form of a tax (or subsidy) on revenues, on capital services and on labor costs, respectively. Given these assumptions, profits are given by:

$$
\pi_{s i}=\left(1-\tau_{y_{s i}}\right) P_{s i} Y_{s i}-\left(1+\tau_{k_{s i}}\right) R_{s} K_{s i}-\left(1+\tau_{h_{s i}}\right) W_{s} H_{s i}-Z_{s} Q_{s i}
$$


where $R_{s}, W_{s}$ and $Z_{s}$ stand for the user cost of capital, labor wage and intermediate inputs price, respectively. ${ }^{2}$

Profit maximization yields the standard conditions that the firm's output price is a fixed markup over marginal cost:

$$
P_{s i}=\frac{\sigma}{\sigma-1} \Psi_{s} \frac{\left(1+\tau_{k_{s i}}\right)^{\alpha_{s}}\left(1+\tau_{h_{s i}}\right)^{\beta_{s}}}{A_{s i}\left(1-\tau_{y_{s i}}\right)}
$$

where

$$
\Psi_{s}=\left[\left(\frac{R_{s}}{\alpha_{s}}\right)^{\alpha_{s}}\left(\frac{W_{s}}{\beta_{s}}\right)^{\beta_{s}}\left(\frac{Z_{s}}{1-\alpha_{s}-\beta_{s}}\right)^{1-\alpha_{s}-\beta_{s}}\right]
$$

In turn, from the first order conditions for profit maximization, we get:

$$
\begin{aligned}
\left(1+\tau_{k_{s i}}\right) & =\frac{\alpha_{s}}{\left(1-\alpha_{s}-\beta_{s}\right)} \frac{Z_{s} Q_{s i}}{R_{s} K_{s i}} \\
\left(1+\tau_{h_{s i}}\right) & =\frac{\beta_{s}}{\left(1-\alpha_{s}-\beta_{s}\right)} \frac{Z_{s} Q_{s i}}{W_{s} H_{s i}} \\
\left(1-\tau_{y_{s i}}\right) & =\frac{\sigma}{\sigma-1} \frac{1}{\left(1-\alpha_{s}-\beta_{s}\right)} \frac{Z_{s} Q_{s i}}{P_{s i} Y_{s i}}
\end{aligned}
$$

Equation (7) allows us to estimate the three wedges from information on gross output, input costs and the elasticities $\sigma, \alpha_{s}$ and $\beta_{s}$.

Next, defining total factor revenue productivity $(T F P R)$ as $T F P R_{s i}=P_{s i} A_{s i}$, we get from equation (5):

$$
T F P R_{s i}=\frac{\sigma}{\sigma-1} \Psi_{s} \frac{\left(1+\tau_{k_{s i}}\right)^{\alpha_{s}}\left(1+\tau_{h_{s i}}\right)^{\beta_{s}}}{\left(1-\tau_{y_{s i}}\right)}
$$

Equation (8) shows that TFPR does not vary across firms within the same industry unless firms face some type of distortion. Intuitively, in the absence of distortions, more capital, labor and intermediate inputs would be allocated to firms with higher $\operatorname{TFP}\left(A_{s i}\right)$ to the point where their higher output results in a lower price and the exact same TFPR as in firms with lower TFP. In contrast, in the presence of distortions, a high (low) TFPR is a sign that the firm confronts barriers (benefits from subsidies) that raise (reduce) the firm's marginal products of the different factors of production, rendering the firm smaller (larger) than optimal.

Denoting the levels of efficient real and nominal output as $Y_{s i}^{*}$ and $\left(P_{s i} Y_{s i}\right)^{*}$, it can be shown (see Dias et al. (2016)) that:

$$
Y_{s i}^{*}=\left(\frac{A_{s i}}{T F P R_{s}^{*}}\right)^{\sigma}=Y_{s i}\left(\frac{T F P R_{s i}}{T F P R_{s}^{*}}\right)^{\sigma}
$$

2. Equation (4) expresses the distortions in terms of output, capital and labor relative to the intermediate inputs distortion. Thus, in the model, an intermediate input distortion will show up as a higher output distortion and as lower capital and labor market distortions. An observationally equivalent characterization would be in terms of distortions to the absolute levels of capital, labor and intermediate input prices (and no output distortion). 


$$
\left(P_{s i} Y_{s i}\right)^{*}=\left(\frac{A_{s i}}{T F P R_{s}^{*}}\right)^{\sigma-1}=P_{s i} Y_{s i}\left(\frac{T F P R_{s i}}{T F P R_{s}^{*}}\right)^{\sigma-1}
$$

where $T F P R_{s}^{*}$ is the efficient level of total factor revenue productivity common to all firms in industry $s$ that will prevail if distortions are eliminated from the industry. $T F P R_{s}^{*}$ is defined so that all firms face the same average wedges, and these are such that the demand for factors of production at the industry level is the same before and after the reallocation of resources. ${ }^{3}$ The average wedges denoted as $\left(1+\bar{\tau}_{k_{s}}\right),\left(1+\bar{\tau}_{h_{s}}\right)$ and $\left(1-\bar{\tau}_{y_{s}}\right)$ are given by the following expressions:

$$
\begin{aligned}
\left(1+\bar{\tau}_{k_{s}}\right) & =\frac{\alpha_{s}}{\left(1-\alpha_{s}-\beta_{s}\right)} \frac{Z_{s} Q_{s}}{R_{s} K_{s}} \\
\left(1+\bar{\tau}_{h_{s}}\right) & =\frac{\beta_{s}}{\left(1-\alpha_{s}-\beta_{s}\right)} \frac{Z_{s} Q_{s}}{W_{s} H_{s}} \\
\left(1-\bar{\tau}_{y_{s}}\right) & =\frac{\sigma}{\sigma-1} \frac{1}{\left(1-\alpha_{s}-\beta_{s}\right)} \frac{Z_{s} Q_{s}}{\left(P_{s} Y_{s}\right)^{*}}
\end{aligned}
$$

where $\left(P_{s} Y_{s}\right)^{*}=\sum_{i=1}^{M_{s}}\left(P_{s i} Y_{s i}\right)^{*}$ is the industry efficient nominal output, $K_{s}=$ $\sum_{i=1}^{M_{s}} K_{s i}, H_{s}=\sum_{i=1}^{\bar{M}_{s}} H_{s i}$ and $Q_{s}=\sum_{i=1}^{M_{s}} Q_{s i}$ are the actual industry levels of the capital stock, labor and intermediate inputs, respectively.

Replacing the firm-specific wedges by the industry average wedges in (8) we have:

$$
\operatorname{TFPR}_{s}^{*}=\frac{\sigma}{\sigma-1} \Psi_{s} \frac{\left(1+\bar{\tau}_{k_{s}}\right)^{\alpha_{s}}\left(1+\bar{\tau}_{h_{s}}\right)^{\beta_{s}}}{\left(1-\bar{\tau}_{y_{s}}\right)}
$$

so that we can decompose the (log) scaled TFPR $\left(T F P R_{s i} / T F P R_{s}^{*}\right)$ for each firm as a weighted sum of the (log) scaled capital, labor and output wedges:

$$
\ln \left(\frac{T F P R_{s i}}{T F P R_{s}^{*}}\right)=\alpha_{s} \ln \left(\frac{1+\tau_{k_{s i}}}{1+\bar{\tau}_{k_{s}}}\right)+\beta_{s} \ln \left(\frac{1+\tau_{h_{s i}}}{1+\bar{\tau}_{h_{s}}}\right)-\ln \left(\frac{1-\tau_{y_{s i}}}{1-\bar{\tau}_{y_{s}}}\right)
$$

This equation allows us to see what happens to the output of the firm if distortions are eliminated from the economy, so that TFPR is equalized across firms in each industry. If scaled TFPR $R_{s i}$ is above one, the firm is being "taxed", so that it will increase production if distortions are eliminated: in the absence of distortions more resources are allocated to this firm to the point where its higher output results in lower price and its TFPR equalizes $T F P R_{s}^{*}$. By looking at the right-hand side of this equation we are able to see where the increase in production comes from. If, for instance, the scaled capital wedge $\left(1+\tau_{k_{s i}}\right) /\left(1+\bar{\tau}_{k_{s}}\right)$ is larger than one, the firm is facing a capital tax, so that

3. $T F P R_{s}^{*}$ should not be confused with $\overline{T F P R}_{s}$ used in Hsieh and Klenow (2009). $\overline{T F P R}_{s}$ in Hsieh and Klenow (2009) is the average TFPR in industry $s$ in the inefficient, or observed, allocation of resources. In contrast, $T F P R_{s}^{*}$ is the average TFPR in industry $s$ when all available factors of production are efficiently allocated. 
it will increase the capital stock if the distortion is eliminated. Similarly, for the scaled labor wedge. In contrast, firms for which the scaled output wedge, $\left(1-\tau_{y_{s i}}\right) /\left(1-\bar{\tau}_{y_{s}}\right)$, is above one, are benefitting from output subsidies, so that they would decrease production if those subsidies are eliminated.

Finally, by combining the various results presented above it is straightforward to write the expression for the real gross-output gains at the industry level:

$$
\begin{aligned}
\frac{Y_{s}^{*}}{Y_{s}} & =\frac{\left[\sum_{i=1}^{M_{s}}\left(Y_{s i}^{*}\right)^{\frac{\sigma-1}{\sigma}}\right]^{\frac{\sigma}{\sigma-1}}}{\left[\sum_{i=1}^{M_{s}}\left(Y_{s i}\right)^{\frac{\sigma-1}{\sigma}}\right]^{\frac{\sigma}{\sigma-1}}}=\left[\frac{\sum_{i=1}^{M_{s}} A_{s i}^{\sigma-1}}{\sum_{i=1}^{M_{s}}\left(A_{s i} \frac{T F P R_{s}^{*}}{T F P R_{s i}}\right)^{\sigma-1}}\right]^{\frac{\sigma}{\sigma-1}} \\
& =\left[\frac{1}{\sum_{i=1}^{M_{s}} \omega_{s i} \cdot\left(\frac{1}{T F P R_{s i} / T F P R_{s}^{*}}\right)^{\sigma-1}}\right]^{\frac{\sigma}{\sigma-1}}
\end{aligned}
$$

where

$$
\omega_{s i}=\left(\frac{A_{s i}}{\left(\sum_{i=1}^{M_{s}} A_{s i}^{\sigma-1}\right)^{\frac{1}{\sigma-1}}}\right)^{\sigma-1}=\left(\frac{A_{s i}}{T F P s^{*}}\right)^{\sigma-1}=\frac{A_{s i}^{\sigma-1}}{\sum_{i=1}^{M_{s}} A_{s i}^{\sigma-1}} .
$$

The interpretation of equation (14) is very intuitive as it is simply the ratio of efficient output to observed output in industry $s$. Note that $\sum_{i=1}^{M_{s}} \omega_{s i}=1$ and that $T F P_{s}^{*}=\left(\sum_{i=1}^{M_{s}} A_{s i}^{\sigma-1}\right)^{(1 /(\sigma-1))}$ is the industry level TFP in the absence of distortions (see Hsieh and Klenow (2009)). Thus, equation (14) shows that efficiency gains in industry $s$ are a weighted sum of the inverse scaled TFPR $\left(1 /\left(T F P R_{s i} / T F P R_{s}^{*}\right)\right)$ across firms, where the weights are the contribution of each firm to the efficient industry TFP. ${ }^{4}$ The smaller is this weighted sum, the larger are the efficiency gains obtained if distortions are eliminated from the industry. In particular, this sum will be small and, thus, efficiency gains will be large if there is a strong positive correlation between the weights $\omega_{s i}$ and the scaled TFPR (TFPR $\left.R_{s i} / T F P R_{s}^{*}\right)$. In other words, efficiency gains will be higher if, on average, more productive firms face higher distortions. From (14), we can also intuitively see that, everything else constant, efficiency gains will be higher the larger the dispersion of scaled TFPR. ${ }^{5}$

4. Using equation (10), it is straightforward to show that these weights also correspond to the firm's gross-output market share, when all resources are efficiently allocated across firms, that is, $\omega_{s i}=\left(P_{s i} Y_{s i}\right)^{*} / \sum_{i=1}^{M_{s}}\left(P_{s i} Y_{s i}\right)^{*}=A_{s i}^{\sigma-1} / \sum_{i=1}^{M_{s}} A_{s i}^{\sigma-1}$.

5. Note that efficiency gains are zero if scaled TFPR is equal to one for all firms, i.e., if there are no distortions in the industry, which means that dispersion of $\left(T F P R_{s i} / T F P R_{s}^{*}\right)$ is zero. Introducing distortions implies, in practice, making the dispersion of $\left(T F P R_{s i} / T F P R_{s}^{*}\right)$ differ from zero. 
Using the Cobb-Douglas aggregator given by equation (1) we get the economy-wide potential gross-output (or TFP) gains from resource reallocation:

$$
\begin{aligned}
\frac{Y^{*}}{Y} & =\prod_{s=1}^{S}\left\{\frac{Y_{s}^{*}}{Y_{s}}\right\}^{\theta_{s}}=\prod_{s=1}^{S}\left\{\left[\frac{\sum_{i=1}^{M_{s}} A_{s i}^{\sigma-1}}{\sum_{i=1}^{M_{s}}\left(A_{s i} \frac{T F P R_{s}^{*}}{T F P R_{s i}}\right)^{\sigma-1}}\right]^{\frac{\sigma}{\sigma-1}}\right\}^{\theta_{s}} \\
& =\prod_{s=1}^{S}\left\{\left[\frac{1}{\sum_{i=1}^{M_{s}} \omega_{s i} \cdot\left(\frac{1}{T F P R_{s i}^{* *}}\right)^{\sigma-1}}\right]^{\theta_{s}}\right\}
\end{aligned}
$$

Equations (14) and (16) will be used to compute industry and economy aggregate gross output reallocation gains, respectively. As the exercise fixes the total amount of inputs and calculates how much gross output could be increased by reallocating resources between firms within each industry, it follows that potential gross-output gains coincide with potential TFP gains, so that (16) gives us the potential efficiency gains both in terms of gross output and TFP. In the empirical section we compute gross-output gains for different groupings of industries (manufacturing vs services) and for each case these formulas will be adjusted accordingly.

\section{The data}

In this paper we use firm-level balance-sheet data and industry-level factor shares. The firm-level data draws on annual information for Portuguese firms reported under the Informação Empresarial Simplificada (IES). IES data exist from 2006 onwards and covers virtually the universe of Portuguese nonfinancial firms. The almost universal coverage of IES emerges from the fact that it is the system through which firms report mandatory information to the tax administration and the statistical authorities like the Instituto Nacional de Estatistica (INE) (the Portuguese Statistics Institute), and the Banco de Portugal (the Portuguese central bank). The data provide very detailed information on the firms' balance sheets and income statements. From this dataset we get information on firm's gross output, value added, consumption of intermediate inputs, labor costs (wages and benefits including social security contributions), employment (average number of employees), gross investment (or gross fixed capital formation), annual and accumulated depreciations, and the book values of gross and net capital stock.

Even though we report results only for 2008 and 2010, we also use data for 2007 and 2009, because we need consecutive years for the construction of some ancillary variables such as productivity shocks. In the IES there are 375,783 observations (different firms) in 2008 and 370,326 observations in 2010. 
Before using the data, we clean the dataset by dropping firms that do not report strictly positive figures for gross output (production), labor costs, employment, capital stock, intermediate consumption and value added. After cleaning the data, we are left with 236,022 and 230,157 observations for 2008 and 2010, respectively.

Table 1 records the relative importance of agriculture, manufacturing and services in our dataset in terms of employment, gross output and value added. Note the small contribution of agriculture for total employment and value added (around 2 percent), while the service sector contributes around 75 percent. Manufacturing, which has been the focus of most empirical studies, contributes only $22-24$ percent to total value added. ${ }^{6}$

\begin{tabular}{lcccccc}
\hline & \multicolumn{3}{c}{2008} & & & 2010 \\
\hline & Agric. & Manuf. & Serv. & Agric. & Manuf. & Serv. \\
\hline Employment & 1.97 & 25.34 & 72.69 & 2.04 & 23.69 & 74.26 \\
Gross output & 2.42 & 34.46 & 63.12 & 1.92 & 32.71 & 65.36 \\
Value added & 2.35 & 23.57 & 74.08 & 1.76 & 22.24 & 76.00 \\
\hline Number of firms & 6,069 & 34,257 & 195,696 & 6,351 & 32,096 & 191,710 \\
\hline
\end{tabular}

Note: Agriculture also includes forestry, fishing, mining and quarrying; Services also include construction and energy.

TABLE 1. Relative importance of each sector in the dataset (Percentage)

The dataset also includes information on the firm's main industry of operation based on NACE classification (Rev. 2.1 and Rev. 3) both at 3- and 5-digit disaggregation level. However, the exercises in our paper are conducted with industries defined at the 3-digit NACE code (Rev. 2.1). In fact, with disaggregation at 5-digit level, the number of firms is very small in many industries implying noisy estimates of industry-level efficiency gains, as well as of some of the regressors used in our analysis. Overall, the 3-digit NACE code classification for 2008 implies 213 different industries (16 for agriculture (including forestry, fishing, mining and quarrying), 101 for manufacturing and 96 for services (including energy and construction)). For 2010 we have 215 industries (16 for agriculture, 101 for manufacturing and 98 for services).

For the industry-level factor shares, we use the average factor shares that are observed in the US during the period 1998 to 2010, which are published by the BEA (Bureau of Economic Analysis). ${ }^{7}$ An important remark to be made

6. According to information from the National Accounts, in 2008, agriculture, manufacturing and services contribute 2.4, 14.1 and 83.5 percent for aggregate GDP, respectively. Thus, if anything, our dataset appears to be slightly skewed towards manufacturing and against the service sector.

7. In our model, it is not possible to separately identify the average input distortions (average wedges) and the input elasticities in each industry. Thus, using factor shares from the U.S. economy is a simple way to control for distortions that could affect the input 
is that, as with the BEA data, our firm-level data on worker compensation include the salaries and other labor costs such as pension contributions or fringe benefits. Because industry classification is different in the two countries we make an approximate concordance between the two classifications. ${ }^{8}$

\section{Misallocation in the manufacturing and service sectors}

In order to take the model to the data we must choose a value for the elasticity of substitution parameter $(\sigma)$, decide how to treat outliers and choose the group of firms included in the analysis. It is known that these assumptions impact the estimated levels of misallocation (see Hsieh and Klenow (2009) or Dias et al. (2016)). Table 2 shows the estimates of efficiency gains for 2008 and 2010, under two sets of assumptions. ${ }^{9}$ The "baseline model" assumes $\sigma=3.0$ (the number usually assumed in the literature), trims 1 percent tails of the scaled TFPR and TFP distributions (also the usual trimming used in the literature) and includes all firms in the dataset. The "final model" assumes $\sigma=4.5$ (the average sigma estimated for Portugal), trims 2.5 percent tails of the scaled TFPR and TFP distributions and excludes very small firms (firms with 10 or less employees).

\begin{tabular}{lcccccccc}
\hline & \multicolumn{9}{c}{2008} & \multicolumn{3}{c}{2010} \\
\hline Assumptions & Total & M & S & S-M & Total & M & S & S-M \\
\hline Baseline model & 43.36 & 16.02 & 59.19 & 43.18 & 49.33 & 16.81 & 66.46 & 49.65 \\
Final model & 28.46 & 14.15 & 37.66 & 23.51 & 31.28 & 14.43 & 40.82 & 26.39 \\
\hline
\end{tabular}

Note: Efficiency gains in the baseline model are computed taking all the firms in the dataset, assuming $\sigma=3.0$ and trimming 1 percent tails of $\log \left(T F P R_{s i} / T F P R_{s}^{*}\right)$ and $\log \left(A_{s i} M^{\frac{1}{\sigma-1}} / T F P_{s}^{*}\right)$. Efficiency gains in the final model are computed taking only firms with more than 10 employees, assuming $\sigma=4.5$ and trimming 2.5 percent tails of the scaled TFPR and TFP distributions. M stands for manufacturing and $S$ for services. S-M is the difference between the service and the manufacturing sectors. The total also includes firms from agriculture.

TABLE 2. Efficiency gains under alternative assumptions

Under the "baseline model" assumptions, we see from Table 2 that if distortions in the economy were eliminated (by equalizing TFPR across firms in each industry and keeping industry level factor demand constant), gross output

shares in the Portuguese economy, while the U.S. is taken as a benchmark of a relatively undistorted economy.

8. In the small number of cases for which we were not able to find a good match, we used the average for the whole economy in the U.S.. Between 1998 and 2010, gross output was composed of 46 percent consumption of intermediate inputs, 33 percent labor compensation and the remaining 21 percent were the compensation to capital owners.

9. In the Appendix we compute the efficiency gains under alternative assumptions and discuss the implications for the estimated level of misallocation and for the difference of allocative efficiency between the service and manufacturing sectors. 
(or TFP) for the whole economy would be around 43 percent above actual gross output (or actual TFP) in 2008 and around 49 percent in 2010. Efficiency gains are also clearly higher in the service sector (around 59 percent in 2008 and 66 percent in 2010) than in the manufacturing sector (around 16 and 17 percent in 2008 and 2010, respectively). Thus, the service sector emerges as far more inefficient than the manufacturing sector in line with the results in Dias et al. (2016). Under the "final model" assumptions, the estimated efficiency gains for the whole economy become smaller: about 28 percent in 2008 and 31 percent in $2010 .^{10}$ The difference between the service and the manufacturing sectors also becomes smaller, but remains very high: about 24 p.p. in 2008 and 26 p.p. in 2010. The decreasing misallocation differences between the two sectors reflect a higher presence of small firms and a higher frequency of outliers in the service sector. By dropping small firms from the dataset and increasing the trimming of the scaled TFP and TFPR distributions, the estimated efficiency gains in the service sector are affected disproportionately.

Figures 1a and $1 \mathrm{~b}$ depict industries ordered by the level of efficiency gains for 2008 under the baseline and the final models, respectively. The striking message from these figures is that the significantly higher levels of efficiency gains in the service sector are the result not of a small number of industries with abnormal levels of efficiency gains, but of a strong regularity: the bulk of the manufacturing sector industries rank first, while the bulk of the service sector industries appear on the right-hand side of the charts. More specifically, among the 50 percent of the industries with the lowest TFP gains (77 industries), only 11 industries (14.7 percent) belong to the service sector in Figure 1a, and only 13 industries (17.3 percent) belong to the service sector in Figure $1 \mathrm{~b}$. This result shows that the presence of higher levels of inefficiency is a widespread phenomenon in the service sector.

In the remainder of this paper, we focus on the "final model" assumptions, as these give rise to more conservative estimates of the differences of misallocation between the two sectors. Using the estimates recorded in Table 2, we conclude that closing the misallocation gap, that is, reducing misallocation in the service sector to the manufacturing levels in 2008 (from 37.66 percent to 14.15 percent) would lead to a 12 percent boost in aggregate gross output (or aggregate TFP) and a 31 percent boost in aggregate value added (GDP). ${ }^{11}$ These are large numbers deserving a thorough investigation of the determinants underlying

10. Note that these figures are for gross output and that the efficiency gains evaluated in terms of value added (the type of estimates usually available in the literature) are significantly higher. For 2008, the corresponding value-added efficiency gains, under the "final model" assumptions, are 71.75 percent for the whole economy, 47.64 percent for manufacturing and 84.05 percent for services.

11. The efficiency gains in terms of gross output are computed as $(1.3766 / 1.1415)^{\theta_{s}}$, where $\theta_{s}$ is the share of the service sector in aggregate gross output. The value-added efficiency gains are computed using equation (24) in Dias et al. (2016). Notice that this exercise is similar to the one carried out in Hsieh and Klenow (2009) where the authors estimate the 


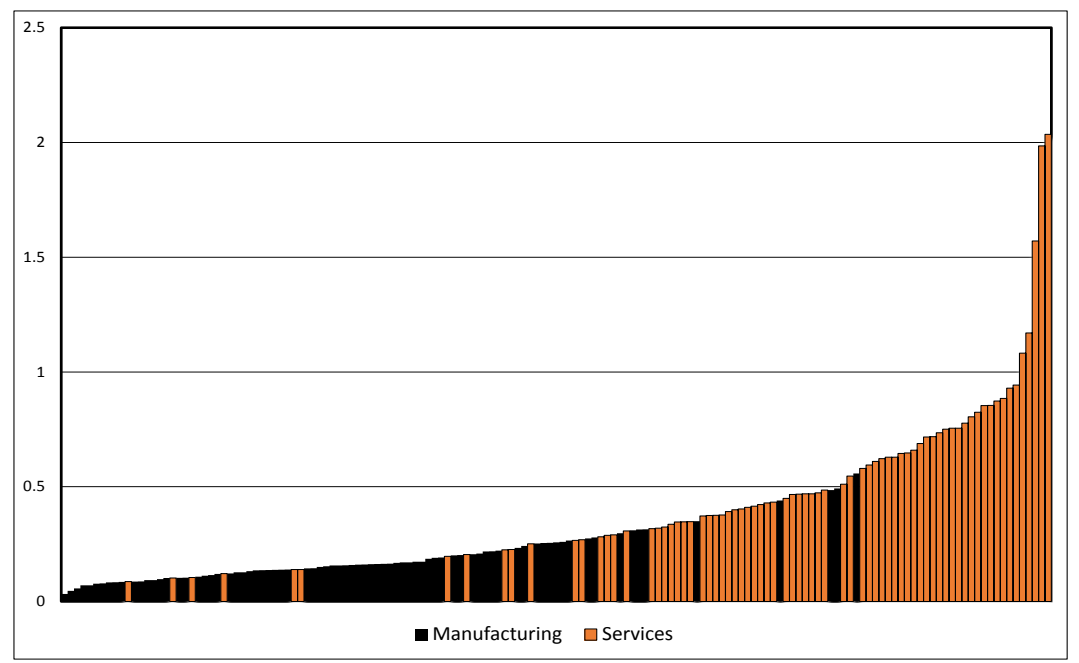

(A) Baseline Model

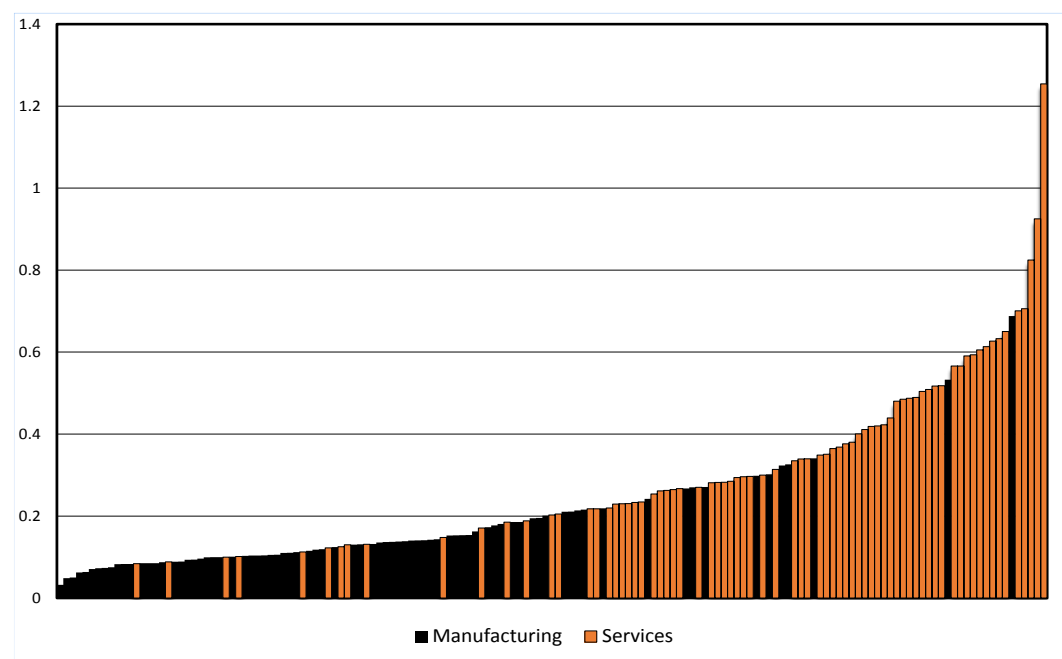

(в) Final Model

Figure 1: TFP gains from reallocation in 2008 - Final model and the U.S.. 
the misallocation gap between the two sectors. In the next section we look to the literature on misallocation and regression analysis to identify the most relevant factors that could explain the difference in misallocation levels between the manufacturing and service sectors.

\section{Explaining differences in misallocation between the service and manufacturing sectors}

In this section, we use regression analysis and the Gelbach decomposition to identify which factors are most relevant for explaining the misallocation differences between the service and manufacturing sectors. We start by reviewing the main theories of misallocation suggested in the literature to guide our identification of the regressors required to complete the model specification. Next, we briefly present the Gelbach decomposition (see Gelbach (2016)) for our model and discuss the empirical results.

\subsection{Theories of misallocation}

The list of potential sources of misallocation suggested by the literature is long and varied. For presentation purposes we group them in four categories: a) adjustment costs; b) distortions to input prices; c) financial frictions; and d) firm-specific markups.

\section{a) Adjustment costs}

The Hsieh and Klenow (2009) model described above is static in the sense that it assumes the adjustments are instantaneous, so that firms should always be in their long-run static equilibrium relationship no matter the frequency, size or type of shocks that hit the firms. Thus, any short-term deviation from the static equilibrium relationship stemming from idiosyncratic shocks and the presence of adjustment costs will show up as misallocation in the model. In a recent paper, Asker et al. (2014) investigated the role of adjustment costs in shaping the dispersion of marginal product of inputs (see also Bartelsman et al. (2013) and Song and Wu (2013)). In their model firms acquire the inputs in a frictionless spot market, but are hit by idiosyncratic productivity shocks and face costs when adjusting their capital stock. In such a framework, dispersion in the marginal revenue product of capital arises naturally and the resource allocation, while appearing as inefficient in a static model, may be efficient in a dynamic sense. An important result for our paper is that, in the presence of adjustment costs, as the volatility of TFP shocks increase, so does the dispersion of the marginal product of the inputs. Thus, in the context of our model, we may expect volatility of TFP shocks to have a bearing on the dispersion of 
TFPR and thus, on misallocation, especially through higher dispersion of the capital and/or labor wedges (see equation (13)). ${ }^{12}$

Another potential source of misallocation, stemming from the static nature of the Hsieh and Klenow (2009) model, is the implicit assumption of instantaneous price adjustment following productivity shocks. According to the model, there is a one-to-one contemporaneous negative relationship between productivity $\left(A_{s i}\right)$ and prices $\left(P_{s i}\right)$ (see equation $(5)$ ). That is, the model assumes that a one percent increase in productivity implies an instantaneous one percent decrease in prices. It is widely known, however, that price stickiness is a pervasive phenomenon in the economy and that firms may react differently to shocks (demand or cost shocks) and asymmetrically to positive and negative shocks. ${ }^{13}$ Thus, similarly to what happens with capital or labor adjustment costs, we may expect firm-level productivity shocks in the presence of pricerigidity to imply additional TFPR dispersion (through higher dispersion of the output wedge) and thus, to give rise to increased misallocation. ${ }^{14}$

We account for the possibility that productivity shocks might help to explain the differences in misallocation between the manufacturing and service sectors. As we will show, this will be the case if the average size of TFP shocks and/or the effect of these shocks differ across the two sectors. If the importance of adjustment costs or the degree of price rigidity varies across industries, we should expect the impact of productivity shocks on misallocation to also differ across industries. If, for instance, on average, price rigidity is higher in the service sector than in manufacturing, we might expect the impact of productivity shocks on misallocation to be higher in the former.

\section{b) Distortions to input prices}

A second potential source of misallocation is the presence of distortions on the prices of the production factors (for a discussion, see Hsieh and Klenow (2009), Guner et al. (2008) or Restuccia and Rogerson (2008), among others). For instance, non-competitive banking systems may offer favorable interest rates on loans to some producers based on non-economic factors, leading to a misallocation of credit across firms. Governments may offer subsidies, special

12. Imperfect information has also been suggested as a foundation for adjustment costs, giving rise to a sluggish response of inputs to fundamentals and thus to misallocation (see David et al. (2014)). In our model it is not possible, however, to distinguish between alternative sources of adjustment costs (technological versus informational frictions).

13. Information costs and/or menu costs incurred by the firm to determine the optimal price and/or to change the price are usually suggested in the literature as the main sources of price rigidity. For empirical evidence on price rigidity at the firm level see, for instance, Fabiani et al. (2006) for the euro area and Dias et al. (2015) for Portugal.

14. Our framework does not allow for distinguishing productivity shocks from other type of shocks. In what follows we use the term productivity shocks to designate a range of timevarying shocks to production that include TFP shocks, demand shocks, natural disasters, changes to informal barriers, etc. 
tax incentives or lucrative contracts to specific producers. Various product and labor-market regulations may drive up the cost of labor in the formal vis-à-vis the informal sector, or in large versus small firms, or drive down the cost of capital in small firms through special lines of credit.

In the case of Portugal there are many regulations that tend to benefit small and medium-sized firms, by granting these firms access to labor and investment subsidies that are not easily accessible or not accessible at all to large firms. These include i) less bureaucratic processes for worker dismissals; ii) less costly conditions regarding the provision of health care services; iii) smaller fines for labor law breaches; iv) better accessibility conditions (including reduction of social contributions) to subsidized employment creation, worker training and professional internship programs; v) better accessibility conditions to investment subsidies, including access to specific investment programs; and vi) access to specific fiscal benefits (smaller taxes on profits)..$^{15}$

In practice, the impact of policies that favor smaller (or larger) firms through lower capital or labor costs is expected to vary across industries depending on the importance of smaller (or larger) firms in each industry. Below, we capture this phenomenon by looking at the skewness of the industry TFP distribution. We use this statistic as a summary measure to characterize the structure of each industry in terms of productivity. By looking at TFP rather than at other measures of size (employment or gross output) we avoid some additional endogeneity problems, as employment and gross output are distortions dependent. ${ }^{16}$ By definition, skewness is high in industries with a high proportion of firms with low productivity, and a few firms with very high productivity. Thus, we interpret the correlation between this statistic and misallocation, at the industry level, as measuring the importance of sizedependent distortions (if distortions were allocated purely randomly across firms the covariance between misallocation and skewness should be zero). Further, by linking productivity to the individual wedges we will be able to tell whether less productive firms are being taxed or subsidized and the source of the tax or the subsidy.

c) Financial frictions

A third potential source of misallocation is the presence of financial frictions. For instance, financial institutions may be unable or unwilling to provide credit to firms that are highly productive but have no credit history or

15. Illustrations of size-dependent polices for Italy and France can be seen in Guner et al. (2008) and Gourio and Roys (2014) and Garicano et al. (2013), respectively.

16. Bartelsman et al. (2013) show that misallocation stemming from policy induced distortions may affect the correlation between the distribution of productivity and the size of the firm. Recall also that, according to the discussion in Section 2, industry-level misallocation will be higher the stronger the (positive) firm-level correlation is between TFP and scaled TFPR. 
insufficient guarantees, preventing these firms from expanding their activities (for a discussion, see Midrigan and Xu (2014), Moll (2014), Gilchrist et al. (2013), Banerjee and Moll (2010) or Hosono and Takizawa (2012), among others). But, financial frictions may instead affect larger firms with larger scales of operation and larger financing needs (see Buera et al. (2011)).

We try to accommodate the possibility that young firms (irrespective of their size) face financial constraints by investigating how misallocation varies with the age of the firm. In practice, our model allows us to distinguish financial frictions that operate as quantity restrictions from size-dependent policies that operate through the price of inputs. The presence of size-dependent policies that affect the price of the inputs may be detected by looking at the relationship between the size of the firm and the individual scaled wedges. For instance, if distortions are due to firm-size contingent policies that favor smaller firms by reducing the cost of capital (through special lines of credit) or the cost of labor (through special labor regulations), returns to additional capital and labor would be expected to be lower in smaller firms. That is, we would expect a positive relationship between size and TFPR or size and the capital or labor wedge. In contrast, if misallocation is due to financial market failures that constrain young firms, we would expect the presence of many of these firms that do not grow because they could not secure access to credit. In other words, we would expect a negative relationship between the age of the firm and the capital wedge. Of course, the two situations may coexist in practice: there may be at the same time small firms that benefit from lower capital costs (special lines of credit) and young firms (eventually small) that are facing capital constraints.

\section{d) Firm-specific markups}

Imperfectly competitive product markets with firm-specific markups have also been suggested as a potential source of misallocation (see, among others, Peters (2013) and Syverson (2004a,b)). In an environment with imperfectly competitive output markets, misallocation, as identified by the static model, occurs because firms have monopoly power and set firm-specific markups. While distortions on the prices of inputs imply that firms with relatively high TFPR are constrained (or "taxed"), imperfectly competitive output markets predict that high TFPR is indicative of market power (captures higher markups). ${ }^{17}$ According to this type of models, industry-level misallocation is expected to be negatively correlated with the level of competition. For instance, barriers to substitution across producers, stemming from various forms of product differentiation (spatial, physical or brand-driven), may explain different levels of misallocation among industries.

17. In the model suggested by Peters (2013), $T F P R_{s i}$ is proportional to the firm-specific markup, which replaces the right-hand side of equation (8). 
To capture the impact of competition on misallocation we need reliable measures of competition across industries. However, satisfactory measures of competition are very difficult to build, either because they are theoretically unsatisfactory or because appropriate data are not available. Statistics such as output concentration ratios, advertising intensity measures, price-cost margins, Herfindahl or the Ellison and Glaeser (1997) concentration indexes, or measures of sunk entry costs or of international exposure do not capture the degree of competition in the relevant markets for all industries. For instance, for Portugal, the concentration ratio (the importance of sales of the largest 4 or 8 firms in total industry sales) is higher in the manufacturing sector than in services. Taken at face value this would mean that the manufacturing sector is less competitive than the service sector. However, the number of firms in the industry or its concentration ratio does not identify the degree of competition in the product market if a significant part of the industry output is exported. What matters is competition in the destination market. Similar comments can be made about most of the other statistics. ${ }^{18}$

Thus, our estimated model does not explicitly include any direct competition measure. However, it is important to note that competition affects the degree of price rigidity, as well as the characteristics of the productivity distribution. We may expect less price rigidity, and thus less misallocation, in industries where competition is higher. Similarly, in industries in which it is easy for customers to switch between competing suppliers, the productivity distributions should exhibit higher minima, less dispersion and lower skewness. Thus, in our empirical model, the skewness of the productivity distribution may also be interpreted as an indirect measure of competition: higher skewness signals lower competition.

\subsection{Gelbach decomposition}

Let us denote the efficiency gains in industry $s$ by $Z_{s}=Y_{s}^{*} / Y_{s}$, and let $D$ be a dummy variable, which equals 1 if the industry belongs to the service sector and 0 if it belongs to the manufacturing sector. ${ }^{19}$ In the simple cross-section regression

$$
Z_{s}=a_{0}+a_{1} D_{s}+u_{s}
$$

the coefficient $a_{1}$ measures the difference between the efficiency gains in the service and manufacturing sectors. The $D_{s}$ variable in the simple regression (17) may be thought of as proxying for differences of certain factors (characteristics) between the manufacturing and service sectors.

18. For a a thorough discussion on this issue see Holmes and Schmitz (2010).

19. In the analysis that follows we drop the agriculture sector, as we are only interested in explaining the differences between misallocation in the manufacturing and service sectors. 
The theories of misallocation, surveyed above, suggest that we should expect industry-level efficiency gains to be correlated with productivity shocks, skewness of the TFP distribution and the proportion of young firms in each industry. Let us denote these three regressors by $X_{1 s}, X_{2 s}$ and $X_{3 s}$, respectively. If we account for the possibility of each regressor having a different impact on the service and manufacturing sectors, the general model may be written as:

$Z_{s}=a_{0}+a_{1} D_{s}+b_{1} X_{1 s}+c_{1} D_{s} X_{1 s}+b_{2} X_{2 s}+c_{2} D_{s} X_{2 s}+b_{3} X_{3 s}+c_{3} D_{s} X_{3 s}+v_{s}$

where the $c_{i}$ coefficient measures the difference of the impact of the $X_{i s}$ regressor between the two sectors. From the estimates for the full model (18), we can tell whether the regressors are able to fully explain the difference between the misallocation in the two sectors. This will be the case if coefficient $a_{1}$ is not statistically different from zero.

The Gelbach decomposition of omitted variable bias allows us to quantify the impact that each variable/factor has on the change in the estimate of $a_{1}$. Using the results in (Gelbach (2016)), we can write:

$$
\widehat{a}_{1}^{\text {base }}=\widehat{a}_{1}^{\text {full }}+\widehat{\theta}_{1} \widehat{b}_{1}+\widehat{\mu}_{1} \widehat{c}_{1}+\widehat{\theta}_{2} \widehat{b}_{2}+\widehat{\mu}_{2} \widehat{c}_{2}+\widehat{\theta}_{3} \widehat{b}_{3}+\widehat{\mu}_{3} \widehat{c}_{3}
$$

where:

a) $\widehat{a}_{1}^{\text {base }}$ and $\widehat{a}_{1}^{\text {full }}$ are the OLS estimate of $a_{1}$ in the base model (equation (17)) and the full model (18), respectively.

b) $\widehat{b}_{i}$ and $\widehat{c}_{i}(\mathrm{i}=1,2,3)$ are the OLS estimates of the $b_{i}$ and $c_{i}$ parameters in the full model (18).

c) $\widehat{\theta}_{i}$ and $\widehat{\mu}_{i}$ are the OLS estimates of the $\theta_{i}$ and $\mu_{i}$ parameters in the simple regressions $X_{i s}=b_{i 0}+\theta_{i} D_{s}+\varepsilon_{i s}$ and $D_{s} X_{i s}=c_{i 0}+\mu_{i} D_{s}+\varepsilon_{i s}, \quad(\mathrm{i}=1,2,3)$, respectively.

In our case, the OLS estimates of the parameters in equation (19) lend themselves to a very intuitive interpretation:

i) $\widehat{a}_{1}^{b a s e}$ is the difference between the efficiency gains in the service and the manufacturing sectors;

ii) $\widehat{a}_{1}^{f u l l}$ is the residual difference between the efficiency gains in the service and manufacturing sectors not accounted for by the model;

iii) $\widehat{\theta}_{i}$ is the difference between the mean of $X_{i s}$ in the service and manufacturing sectors, and

iv) $\widehat{\mu}_{i}$ is the mean of $X_{i s}$ in the service sector.

The total contribution of the $X_{i s}$ regressor is given by $\widehat{\theta}_{i} \widehat{b}_{i}+\widehat{\mu}_{i} \widehat{c}_{i}$. Thus, $X_{i s}$ accounts for the difference between the efficiency gains in the two sectors, if at least one of the two conditions is met: $\mathrm{i}$ ) the mean of $X_{i s}$ differs across the two sectors $\left(\widehat{\theta}_{i} \neq 0\right)$, or ii) the impact of $X_{i s}$ differs between the two sectors $\left(\widehat{c}_{i} \neq 0\right){ }^{20}$

20. We note that the Gelbach decomposition for our particular model is similar to the so-called Oaxaca-Blinder decomposition that has been extensively used in the literature 


\subsection{Regression analysis}

The results of decomposition (19) are presented in Table 3 for 2008 and 2010, with robust standard errors in parentheses. The first row records the $\widehat{a}_{1}^{\text {base }}$ estimates, that is, the difference between efficiency gains in the service and manufacturing sectors. ${ }^{21}$ The second row reports the explained difference, that is, the sum of contributions of the 3 regressors. The second row from bottom records the unexplained difference, that is, $\widehat{a}_{1}^{f u l l}$. For each regressor $X_{i s}$, the total contribution is divided into two components: one stemming from the difference between the mean of the regressors in the two sectors (characteristics effect), and one stemming from the difference of the regressors impact in the two sectors (coefficients effect).

An important result is that the model fully accounts for the difference between the efficiency gains in the two sectors. The unexplained difference, that is, $\widehat{a}_{1}^{f u l l}$, is not significantly different from zero both in 2008 and 2010. Similar to Figures $1 \mathrm{a}$ and $1 \mathrm{~b}$, if we now order industries by the level of unexplained efficiency gains in 2008, we conclude that among the 50 percent of the industries with the lowest TFP gains (77 industries), 43 industries (58.1 percent) belong to the service sector (compared to 17.3 percent in Figure 1b). These numbers suggest that our model is able to explain the misallocation differences between industries of the two sectors to the point where no systematic differences of TFP gains in the two sectors remain.

\section{a) Productivity shocks}

Productivity shocks emerge as the most important factor explaining misallocation differences between the two sectors. ${ }^{22}$ Importantly, the contribution of productivity shocks stems mostly from the difference of the impacts between the two sectors (coefficients effect). In particular, the impact of productivity shocks in the service sector is significantly higher than in

to decompose mean wage differentials (see, for instance, Blinder (1973), Oaxaca (1973) and Jann (2008)). One important difference, however, is that the methodology developed in Gelbach (2016) allows for statistical inference regarding the decomposition, while the Oaxaca-Blinder method did not.

21. Note that the difference in efficiency gains between the two sectors in Table 3 is a non-weighted average, which explains the difference vis- $a$-vis the figures reported in the last row of Table 2 .

22. To identify the productivity shocks, we assume that TFP follows an AR(1) process: $a_{s i, t}=\mu_{s}+\rho_{s} a_{s i, t-1}+\varphi_{s} v_{s i, t}$, where $a_{s i, t}$ stands for the log of TFP of firm $i$, in industry $s$, in period $\mathrm{t}$, and $v_{s i, t} \sim N(0,1)$ is an independent and identically distributed (i.i.d.) standard normal random variable. The $\varphi_{s}$ term measures productivity shocks in industry $s$. To estimate $\varphi_{s}$ we use two years of consecutive data, but restrict the sample to firms that appear in both years. When estimated freely, $\rho_{s}$ is close to unity for the great majority of industries. Thus, ultimately, we compute the productivity shocks as the industry-level standard deviation of $\left(a_{s i, t}-a_{s i, t-1}\right)$. 
the manufacturing sector. This is an interesting result that warrants some explanations.

\begin{tabular}{|c|c|c|}
\hline & 2008 & 2010 \\
\hline Difference in efficiency gains & $\begin{array}{l}0.202 \\
(8.31)\end{array}$ & $\begin{array}{l}0.205 \\
(7.90)\end{array}$ \\
\hline Explained difference: & $\begin{array}{l}0.225 \\
(2.36)\end{array}$ & $\begin{array}{l}0.207 \\
(2.45)\end{array}$ \\
\hline a) Productivity shocks & $\begin{array}{l}0.175 \\
(1.82)\end{array}$ & $\begin{array}{l}0.123 \\
(1.64)\end{array}$ \\
\hline$\left.a_{1}\right)$ characteristics effect & $\begin{array}{l}0.027 \\
(1.77)\end{array}$ & $\begin{array}{l}0.023 \\
(2.17)\end{array}$ \\
\hline$\left.a_{2}\right)$ coefficients effect & $\begin{array}{l}0.148 \\
(1.44)\end{array}$ & $\begin{array}{l}0.099 \\
(1.23)\end{array}$ \\
\hline b) Sectoral firm-size structure & $\begin{array}{l}0.086 \\
(2.60)\end{array}$ & $\begin{array}{l}0.113 \\
(3.07)\end{array}$ \\
\hline$\left.b_{1}\right)$ characteristics effect & $\begin{array}{l}0.016 \\
(2.15)\end{array}$ & $\begin{array}{l}0.002 \\
(0.33)\end{array}$ \\
\hline$\left.b_{2}\right)$ coefficients effect & $\begin{array}{l}0.069 \\
(2.00)\end{array}$ & $\begin{array}{l}0.112 \\
(2.85)\end{array}$ \\
\hline c) Importance of young firms & $\begin{array}{l}-0.036 \\
(-0.96)\end{array}$ & $\begin{array}{l}-0.029 \\
(-0.97)\end{array}$ \\
\hline$\left.c_{1}\right)$ characteristics effect & $\begin{array}{l}0.021 \\
(1.83)\end{array}$ & $\begin{array}{l}0.014 \\
(1.70)\end{array}$ \\
\hline$\left.c_{2}\right)$ coefficients effect & $\begin{array}{l}-0.057 \\
(-1.32) \\
\end{array}$ & $\begin{array}{l}-0.042 \\
(-1.37) \\
\end{array}$ \\
\hline Unexplained difference & $\begin{array}{l}-0.023 \\
(-0.26)\end{array}$ & $\begin{array}{l}-0.002 \\
(-0.02)\end{array}$ \\
\hline Number of industries & 154 & 154 \\
\hline
\end{tabular}

Note: Efficiency gains are obtained assuming case (8) in Table 2. Difference in efficiency gains is given by the coefficient of the industry-dummy in regression (17), while the unexplained difference is given by the coefficient of the industry-dummy in regression (18). Robust t-statistics in parentheses.

TABLE 3. Differences in misallocation between services and manufacturing: Gelbach decompositions

For reasons discussed above, we expect industry-level efficiency gains to be positively correlated with productivity shocks. In the presence of adjustment costs, a firm can adjust capital or labor only with some lag as it takes time to install capital or to hire new employees. A similar process takes place in the presence of output price rigidity. Thus, when hit by an idiosyncratic productivity shock, a firm responds with a lag and adjusts the input level or the output price sluggishly, which leads to variation of TFPR across firms. With this lagged response, greater idiosyncratic shocks lead to greater variation of TFPR across firms and thus, to greater misallocation. However, for the impact of productivity shocks on misallocation to differ across sectors, we need to assume that the importance of input adjustment costs (capital and/or labor) or the degree of price rigidity vary across industries.

In order to investigate this issue further, we use equation (13) to look at the correlation between TFP shocks and the dispersion of individual wedges. This analysis allows us to tell whether the impact of TFP shocks on misallocation stems mainly from the presence of capital, labor or output distortions. Table (4) reports these correlations for 2008. 


\begin{tabular}{lcccccc}
\hline & \multicolumn{2}{c}{ TFP-shocks } & \multicolumn{2}{c}{ Sectoral structure } & \multicolumn{2}{c}{ Share young firms } \\
\hline & Manuf & Serv & Manuf & Serv & Manuf & Serv \\
\hline $\operatorname{sd}\left(\right.$ tau $\left._{k}\right)$ & 0.114 & 0.059 & 0.212 & -0.089 & 0.302 & 0.225 \\
$\operatorname{sd}\left(\right.$ tau $\left._{h}\right)$ & 0.108 & 0.418 & 0.084 & 0.241 & 0.308 & 0.233 \\
$\operatorname{sd}\left(\right.$ tauy $\left._{y}\right)$ & 0.342 & 0.393 & 0.299 & 0.163 & 0.398 & 0.160 \\
$\operatorname{sd}($ tfpr $)$ & 0.337 & 0.456 & 0.264 & 0.228 & 0.359 & 0.153 \\
\hline
\end{tabular}

Note: Entries are the correlations between the regressors and the industry-level standarddeviations of scaled TFPR and scaled wedges; sd(x) stands for the industry-level standard deviation of $\ln (\mathrm{x})$; TFP-shocks are proxied by the industry-level standard deviation of firms' $\log$ TFP changes between year $\mathrm{t}$ and year $\mathrm{t}-1$; the sectoral structure is proxied by the skewness of the productivity distribution and the importance of young firms is proxied by the proportion of firms with three years of age or less.

TABLE 4. Correlation between the regressors and the standard-deviations of scaled TFPR and scaled wedges (2008)

An interesting result from Table 4 is that productivity shocks are not very correlated with the standard-deviation of the capital wedge, especially in the service sector. ${ }^{23}$ In contrast, productivity shocks appear more correlated with the labor-wedge and output-wedge dispersion in the service sector than in the manufacturing sector. This evidence is consistent with the idea of higher price rigidity and higher labor adjustment costs in the service sector. The empirical evidence in the literature has shown that price rigidity is higher in the service sector (see, for instance, Fabiani et al. (2006) for the euro area, and Dias et al. (2015) for Portugal). It is also known that price rigidity is higher in less competitive markets (Martin (1993), Gopinath and Itskhoki (2010)). Together, this evidence suggests that higher output price rigidity in the service sector might stem from lower competition in this sector, as services are typically more differentiated than manufacturing (see ECB (2006)). ${ }^{24}$ In turn, higher informational frictions (stemming from higher spatial dispersion of firms due to local markets) might explain why labor adjustment costs appear to be higher in the service sector. Thus, together, higher output price rigidity and higher labor adjustment costs emerge as the explanations for the higher impact of productivity shocks on misallocation in the service sector.

\section{b) Sectoral firm-size structure}

The sectoral firm-size structure, as proxied by the skewness of the productivity distribution, emerges as the second most important factor to explaining misallocation differences between the two sectors. As explained above, we use the skewness of the productivity distribution as a way of summarizing the industry-level characteristics that may affect the impact on

23. Of course, this does not necessarily mean that capital adjustment costs are not present in the economy, as the adjustment costs are not the only source of dispersion of the marginal product of capital.

24. Of course, besides competition, there might be other factors that contribute to higher price rigidity in the service sector, such as higher information or search costs due to higher geographical dispersion. 
misallocation of size-dependent distortions. ${ }^{25}$ The aggregate impact of sizedependent policies varies across industries according to the characteristics of the size distribution of each industry. In an economy where special lines of credit (with subsidized interest rates) or employment subsidies are available to small and medium sized firms, we would expect industries with higher skewness to exhibit higher misallocation.

From Table 3 we see that the bulk of the contribution of the sectoral firm-size structure comes from the higher impact of this regressor in the service sector (coefficients effect). According to the evidence presented in Table 5, which records the correlation coefficients between TFP, TFPR and its components, the higher impact of skewness on misallocation in the service sector must reflect the higher positive correlation between productivity and TFPR in this sector ( 0.70 in the service sector compared to 0.43 in the manufacturing sector, in 2008). This higher positive correlation in the service sector means that there must be size-dependent distortions in this sector that are not present, or are present to a lesser extent, in the manufacturing sector.

\begin{tabular}{|c|c|c|c|c|}
\hline & \multicolumn{2}{|c|}{2008} & \multicolumn{2}{|c|}{2010} \\
\hline & Manuf & Serv & Manuf & Serv \\
\hline$\overline{\operatorname{corr}\left(t f p, t a u_{k}\right)}$ & 0.291 & 0.387 & 0.303 & 0.384 \\
\hline $\operatorname{corr}\left(t f p, t_{a u_{h}}\right)$ & 0.407 & 0.314 & 0.442 & 0.297 \\
\hline $\operatorname{corr}\left(t f p, t_{a}\right)$ & 0.156 & 0.046 & 0.167 & 0.026 \\
\hline $\operatorname{corr}(t f p, t f p r)$ & 0.431 & 0.696 & 0.448 & 0.693 \\
\hline $\operatorname{corr}\left(t f p, t f p r+t a u_{y}\right)$ & 0.437 & 0.424 & 0.462 & 0.419 \\
\hline
\end{tabular}

Note: $\operatorname{corr}(t f p, x)$ stands for the correlation between $\log ($ scaled TFP) and $\log (\mathrm{x})$, where $\mathrm{x}$ represents scaled TFPR or one scaled wedge. Figures correspond to the (non-weighted) average of the industry-level correlations.

TABLE 5. Correlation between scaled TFP, scaled TFPR and the scaled wedges (average industry-level correlations)

Figure 2, which depicts the relationship between firm-level scaled productivity and scaled wedges, allows us to further characterize the size dependent distortions prevailing in the two sectors. ${ }^{26}$ From the figure, we conclude that less productive firms are being subsidized, on average, both in the manufacturing and service sectors (log of the scaled TFPR is negative for less

25. Skewness of the productivity distribution is computed using the usual Fisher-Pearson formula: $s k_{s}=\sum_{i=1}^{M s}\left(X_{s i}-\overline{X_{s}}\right)^{3} / S D\left(X_{s}\right)^{3}$, where $X_{s i}$ stands for scaled $T F P_{s i}$ and $\operatorname{SD}\left(X_{s}\right)$ for the standard deviation of $X_{s}$, with $X_{s i}=\left(A_{s i} M_{s}^{\frac{1}{\sigma-1}} / T F P_{s}^{*}\right)$ and $T F P_{s}^{*}$ is as defined above. We note that skewness is a measure of asymmetry of the distribution about its mean. Positive skewness indicates that the tail of the distribution on the right hand side is longer or fatter than the left side. In a positive skewed distribution, usually the mean is greater than the mode, which means that there are a lot of firms with low productivity levels (below the mean) and a few firms with productivity far above the mean.

26. Figures 2 and 3 are obtained by fitting a kernel-weighted local polynomial smoothing to the data, with kernel=epanechnikov and degree $=1$. 
productive firms in the bottom panel of Figure 2), and that these subsidies come from relatively lower capital and lower labor costs in these firms. Despite being obtained from firm-level data, the implicit correlations (steeper slope for the capital wedge in the service sector and steeper slope for the labor wedge in the manufacturing sector) appear fully consistent with the sector-level correlations in Table 5. But, what distinguishes the two sectors, in qualitative terms, is the output wedge. In the manufacturing sector, firms, on average, appear to face output "taxes" (negative figures of the log scaled output wedge) for a large range of scaled productivity levels, which offset to some extent the capital and labor "subsidies" in terms of scaled TFPR. However, in the service sector, firms appear to benefit from output "subsidies", on average, which add to capital and labor "subsidies" in the case of less productive firms. This evidence in Figure 2 translates into the significantly lower correlation between productivity and the output wedge in the service sector (0.047), compared to the manufacturing sector $(0.155)$, seen in Table $5 .^{27}$ In order to evaluate the impact of the output distortions for the correlation between TFP and TFPR, we also computed the correlation between TFP and TFPR excluding the output wedge component (see equation (13)). The numbers reported in the last row of Table 5 show that if we exclude the impact of the output wedge, the correlation between TFP and TFPR changes significantly in the service sector, and becomes about the same in the two sectors.

Summing up, the capital and labor wedge have correlations with productivity that differ across sectors but that tend to offset each other, so that ultimately it is the difference between the output wedge in the two sectors that is responsible for the higher correlation between TFP and TFPR in the service sector. At first sight, it is not clear why the output wedge should be so different in the two sectors. If we look at equations (7) and (11), which define the scaled output wedge, we can see that firms misreporting sales (for tax reasons, for instance) will tend to show up in the model as less productive firms, both in terms of TFP and of TFPR and so, as benefiting from output subsidies (they appear as producing more than what they should given their TFP levels). Evidence suggests that informality is higher in the service sector, partly stemming from characteristics of the sector that make tax collection enforcement much more difficult than in the manufacturing sector. We believe that this might be part of the story behind the documented difference between the two sectors, and this is an issue deserving further investigation.

27. Note that, according to equation (13), the lower the correlation between productivity and the output wedge the higher the correlation between productivity and TFPR. 

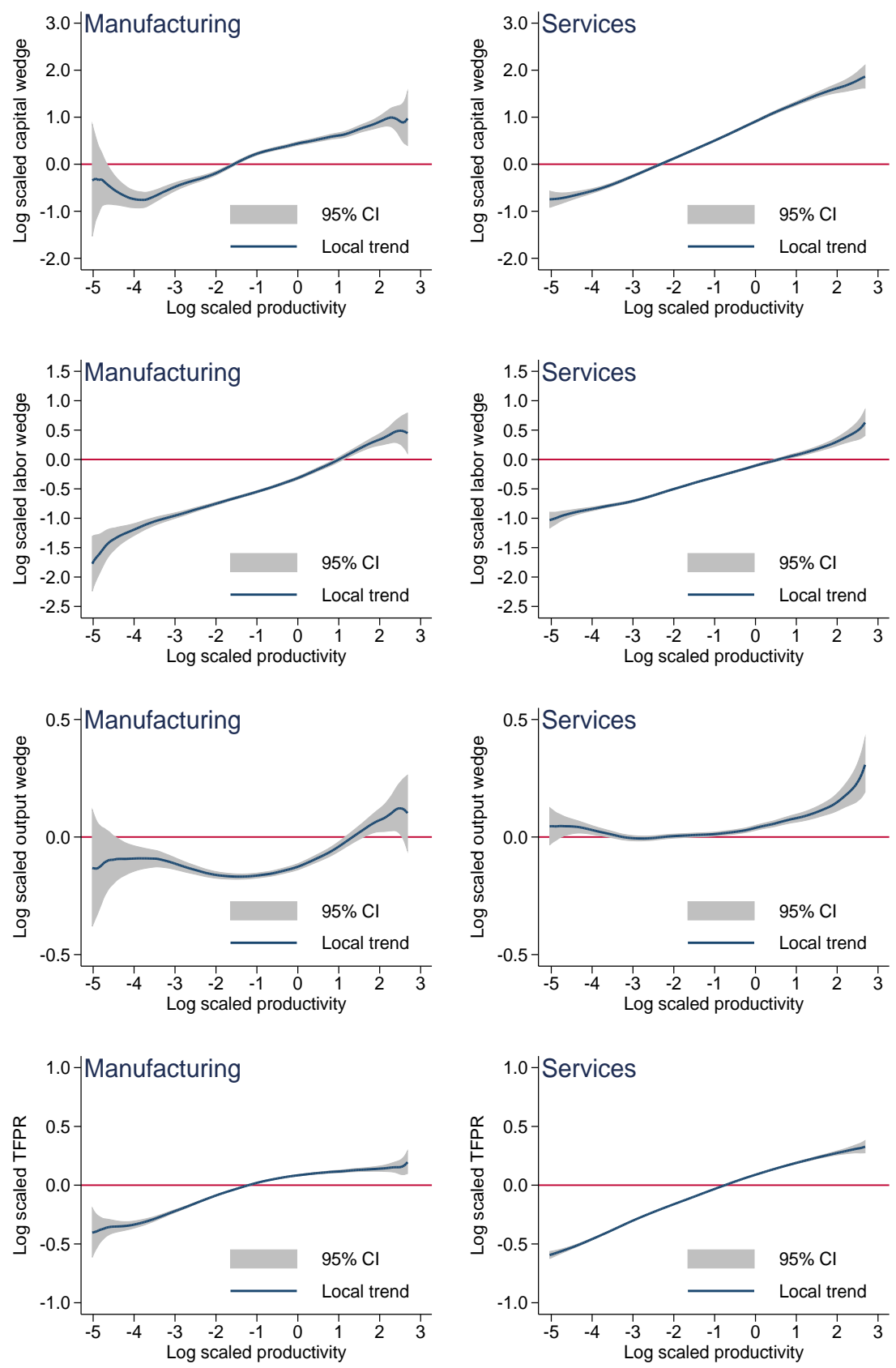

Figure 2: Wedges and productivity - 2008 

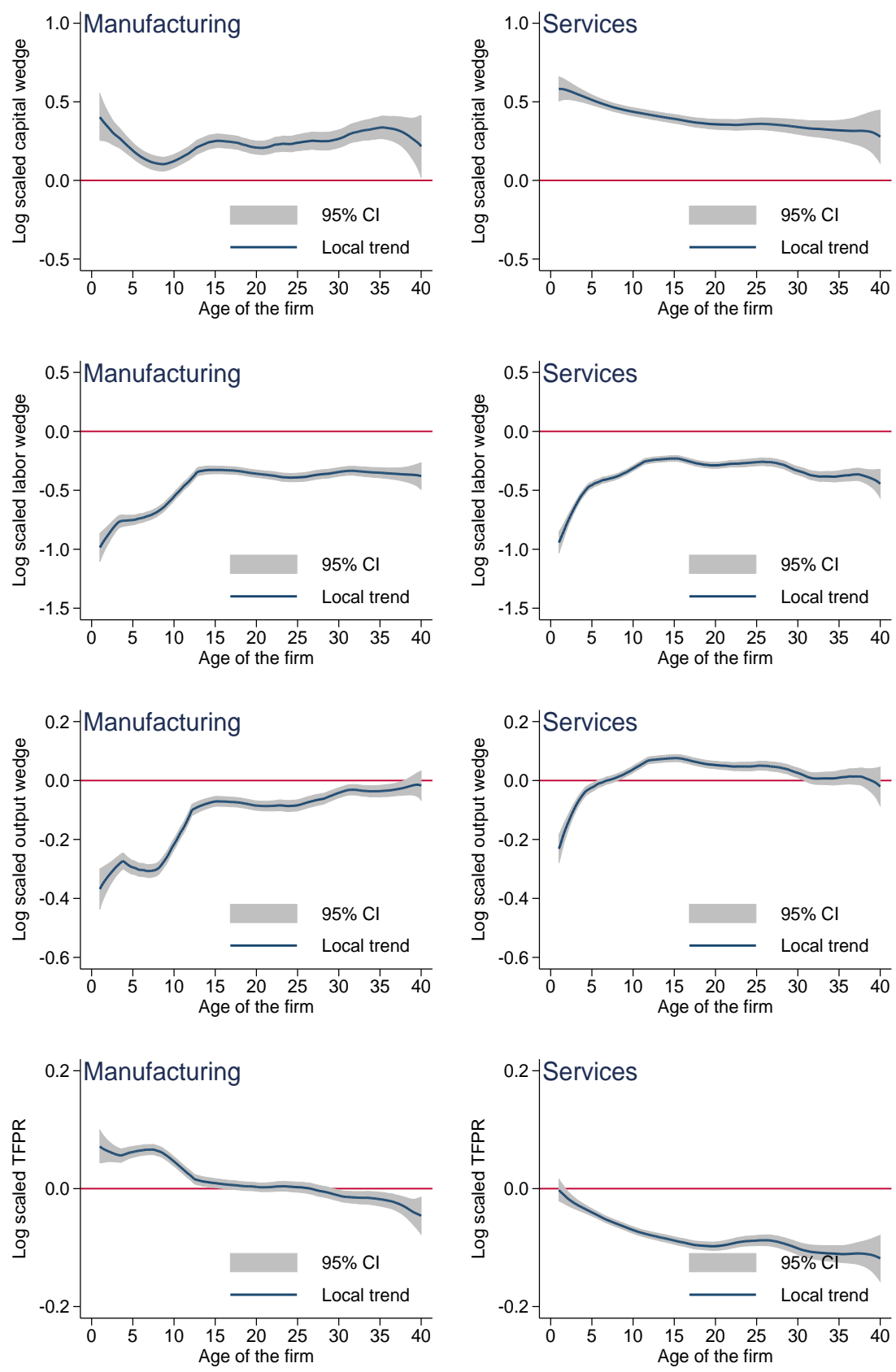

Figure 3: Wedges and age of the firm - 2008 


\section{c) Importance of young firms}

Finally, according to our model, the proportion of young firms also has a bearing on the difference in misallocation between the two sectors. ${ }^{28}$ From Table 3, we conclude that this regressor contributes with two opposite effects to the difference in misallocation between the manufacturing and the service sectors. On the one hand, the impact of the difference in the mean of this regressor between the manufacturing and service sectors (characteristics effect) contributes to increasing the difference in misallocation between the two sectors (2.1 p.p. in 2008), but the difference in the impact of the regressor between the two sectors (coefficients effect) has the opposite effect (-5.7 p.p.), so that the total impact of this regressor is negative (-3.6 p.p.). This means that the impact on misallocation from the proportion of young firms is lower in the service sector, and that, in the absence of this effect, the difference in misallocation between the service and manufacturing sectors would be even higher.

Figure 3, which depicts the relationship between firms' age and scaled wedges, shows that despite benefiting from lower labor costs (lower scaled labor wedge), young firms, on average, face higher distortions (higher TFPR) than older firms, stemming from higher capital costs and higher output distortions. We link the higher capital costs to the presence of credit constraints imposed by financial institutions on young firms because of a lack of credit history or insufficient guarantees. ${ }^{29}$ From Table 4 , we see that the correlation between the proportion of young firms and the standard deviation of the individual wedges is lower in the service sector for all three wedges, suggesting that all distortions contribute to the lower impact of this regressor in the service sector (negative coefficients effect). Nevertheless, as in the case of the skewness regressor, the output wedge appears to be mainly responsible for the differences in the impact of this regressor between the two sectors: output distortions in young firms are much less important in the service sector than in manufacturing, contributing significantly to the smaller contrast between younger and older firms in the former.

\section{Conclusions}

The empirical literature on misallocation has recently documented that the level of allocative efficiency in the service sector is significantly lower than that of the manufacturing sector. Because services are, by far, the most important sector of activity in most economies nowadays, significantly higher levels of

28. We proxy the importance of young firms at the industry level by the ratio of the number of firms 3 years of age or less to the total number of firms.

29. Note the qualitative differences vis-à-vis the evidence in Figure 2, where small firms appear as benefitting from capital subsidies, on average. 
misallocation in this sector have important implications for aggregate TFP and aggregate GDP.

Using firm-level data for the Portuguese economy, we document that the significantly higher levels of allocative inefficiency in the service sector are not the result of a small number of industries with abnormal levels of inefficiency, but rather the outcome of a strong regularity. The great majority of the industries belonging to the manufacturing sector rank among the industries with the lowest misallocation. Conservative estimates for Portugal suggest that resource misallocation in 2008 was around 24 percentage points higher in the service than in the manufacturing sector. Closing this misallocation gap, that is, reducing misallocation in the service sector to the manufacturing levels would lead to a 12 percent boost in aggregate gross output (or aggregate TFP) and a 31 percent boost in aggregate value added (GDP).

Using regression analysis, we are able to fully explain the difference between efficiency gains in the two sectors. Productivity shocks, which capture the impact of (capital/labor) adjustment costs and/or output-price rigidity on misallocation, emerge as the most important factor contributing to the differences in misallocation between the two sectors. This contribution stems more from differences in the impacts of productivity shocks on misallocation, than from differences in these shocks between the two sectors. The bulk of the difference in misallocation due to productivity shocks is likely to originate from the presence of higher output-price rigidity and higher labor adjustment costs in the service sector.

The sectoral firm-size structure, which captures the impact of sizedependent distortions on misallocation, and is proxied by the skewness of the productivity distribution, emerges as the second most important factor to explain the difference in misallocation between the two sectors. Also in this case, the bulk of the contribution comes from differences in the impact and not from differences in the mean of the regressor between the two sectors. The higher impact of this regressor on the service sector stems mainly from a higher level of informality that makes tax collection enforcement more difficult than in the manufacturing sector.

Finally, the empirical model suggests that the proportion of young firms also has a bearing on the misallocation differences between the two sectors, but its impact in the service sector is lower. We link this regressor to the presence of barriers to growth, stemming, for instance, from credit constraints imposed by financial institutions on young firms because they have no credit history or insufficient guarantees.

The fact that we are able to fully explain the differences of allocative efficiency between the manufacturing and service sectors suggests that such differences originate from identifiable theoretical sources of misallocation and not from higher unexplainable heterogeneity in the service sector that would make the Hsieh and Klenow $(2009,2011)$ methodology not applicable to the service sector. 
Our findings have important implications for economic policy. A significant part of the difference of allocative efficiency between the two sectors may be attributed to higher output price rigidity in the service sector. To the extent that such higher price rigidity stems from lower competition, measures aimed at increasing product market competition in the service sector will contribute to increasing allocative efficiency in the sector and thus, boosting aggregate productivity.

Less productive firms appear as benefitting from capital and labor subsidies, which suggests that there might be a trade-off between employment creation and aggregate productivity. Therefore, size-contingent laws passed by governments and aimed at boosting employment creation in small or mediumsized firms (special lines of credit with subsidized interest rates and/or labor subsidies), to the extent that they contribute to the survival of unproductive firms, especially in the service sector, where competition is weaker, will increase misallocation and have a strong negative impact on aggregate productivity. Finally, eliminating or minimizing the impact of financial constraints on young firms would also contribute to increasing aggregate productivity. 


\section{References}

Adamopoulos, Tasso and Diego Restuccia (2014). "The Size Distribution of Farms and International Productivity Differences." American Economic Review, 104(6), 1667-97.

Amador, Joao and Ana Cristina Soares (2013). "Competition in the portuguese economy: Estimated price-cost margins under imperfect labour markets." Working Paper 8, Banco de Portugal.

Asker, John, Allan Collard-Wexler, and Jan De Loecker (2014). "Dynamic Inputs and Resource (Mis)Allocation." Journal of Political Economy, 122(5), 1013 - 1063.

Banerjee, Abhijit V. and Benjamin Moll (2010). "Why does misallocation persist?" American Economic Journal: Macroeconomics, 2(1), 189-206.

Bartelsman, Eric, John Haltiwanger, and Stefano Scarpetta (2013). "Crosscountry differences in productivity: The role of allocation and selection." American Economic Review, 103(1), 305-334.

Bellone, Flora and Jérémy Mallen-Pisano (2013). "Is Misallocation Higher in France than in the United States?" GREDEG Working Papers 201338, Groupe de REcherche en Droit, Économie, Gestion (GREDEG CNRS), University of Nice-Sophia Antipolis.

Benkovskis, Konstantins (2015). "Misallocation of resources in Latvia: did anything change after the crisis?" Working Paper 5, Bank of Latvia.

Blinder, A. S. (1973). "Wage discrimination: Reduced form and structural estimates." Journal of Human Resources, 8(4), 436-455.

Buera, Francisco J., Joseph Kaboski, and Yongseok Shin (2011). "Finance and Development: A Tale of Two Sectors." American Economic Review, 101(5), 1964-2002.

Calligaris, Sara (2015). "Misallocation and Total factor productivity in Italy: Evidence from firm-level data." Research Paper Series 357, Centre for Economic and International Studies.

Camacho, Adriana and Emily Conover (2010). "Misallocation and Productivity in Colombia's Manufacturing Industries." Working Paper IDB-WP-123, Inter-American Development Bank.

Chen, Kaiji and Alfonso Irarrazabal (2015). "The Role of Allocative Efficiency in a Decade of Recovery." Review of Economic Dynamics, 18(3), 523-550.

Christopoulou, Rebekka and Philip Vermeulen (2012). "Markups in the Euro area and the US over the period 1981-2004: a comparison of 50 sectors." Empirical Economics, 42(1), 53-77.

David, Joel M., Hugo A. Hopenhayn, and Venky Venkateswaran (2014). "Information, Misallocation and Aggregate Productivity." NBER Working Paper 20340, National Bureau of Economic Research, Inc.

Dias, D. A., Carlos Robalo Marques, and Christine Richmond (2016). "Misallocation and productivity in the lead up to the Eurozone crisis." Journal of Macroeconomics, 49, 46-70. 
Dias, Daniel A., Carlos Robalo Marques, Fernando Martins, and J. M.C. Santos Silva (2015). "Understanding Price Stickiness: Firm Level Evidence on Price Adjustment Lags and Their Asymmetries." Oxford Bulletin of Economics and Statistics, 77(5), 701-718.

Duarte, Margarida and Diego Restuccia (2010). "The role of the structural transformation in aggregate productivity." The Quarterly Journal of Economics, 125(1), 129-173.

ECB (2006). "Competition, Productivity and Prices in the Euro Area Services Sector." Working Paper Series 44, European Central Bank.

Ellison, Glenn and Edward L. Glaeser (1997). "Geographic Concentration in U.S. Mnufacturing Industries: A dartboard approach." Journal of Political Economy, 105(5), 889-927.

Fabiani, Silvia, Martine Druant, Ignacio Hernando, Claudia Kwapil, Bettina Landau, Claire Loupias, Fernando Martins, Thomas Mathä, Roberto Sabbatini, Harald Stahl, and Ad Stokman (2006). "What Firms' Surveys Tell Us about Price-Setting Behavior in the Euro Area." International Journal of Central Banking, 2(3).

Garcia-Santana, Manuel, Enrique Moral-Benito, Josep Pijoan-Mas, and Roberto Ramos (2015). "Growing like Spain: 1995-2007." mimeo.

Garicano, Luis, Claire LeLarge, and John Van Reenen (2013). "Firm Size Distortions and the Productivity Distribution: Evidence from France." Working Paper 18841, National Bureau of Economic Research.

Gelbach, Jonah B. (2016). "When Do Covariates Matter? And Which Ones, and How Much?" Journal of Labor Economics, 34(2), 509-543.

Gilchrist, Simon, Jae W. Sim, and Egon Zakrajsek (2013). "Misallocation and financial market frictions: Some direct evidence from the dispersion in borrowing costs." Review of Economic Dynamics, 16, 159-176.

Gopinath, Gita and Oleg Itskhoki (2010). "Frequency of price adjustment and pass-through." The Quarterly Journal of Economics, 125(2), 675-727.

Gopinath, Gita, Sebnem Kalemli-Ozcan, Loukas Karabarbounis, and Carolina Villegas-Sanchez (2015). "Capital Allocation and Productivity in South Europe." Working Paper 21453, National Bureau of Economic Research.

Gourio, François and Nicolas Roys (2014). "Size-dependent regulations, firm size distribution, and reallocation." Quantitative Economics, 5, 377-416.

Guner, Nezih, Gustavo Ventura, and Xu Yi (2008). "Macroeconomic Implications of Size-Dependent Policies." Review of Economic Dynamics, 11(4), 721-744.

Holmes, Thomas J. and James A. Schmitz (2010). "Competition and Productivity: A review of Evidence." Research Department Staff Report 439, Federal Reserve Bank of Minneapolis.

Hosono, Kaoru and Miho Takizawa (2012). "Do financial frictions matter as a source of misallocation? Evidence from Japan." PRI Discussion Paper Series 12A-17, Policy Research Institute. 
Hsieh, Chang-Tai and Peter J. Klenow (2009). "Misallocation and Manufacturing TFP in China and India." The Quarterly Journal of Economics, 124(4), 1403-1448.

Hsieh, Chang-Tai and Peter J. Klenow (2011). "Misallocation and Manufacturing TFP in China and India: Correction Appendix." Stanford University. Unpublished.

Jann, Ben (2008). "The Blinder-Oaxaca decomposition for linear regression models." The Stata Journal, 8(4), 453-479.

Machicado, Carlos Gustavo and Juan Cristobal Birbuet (2012). "Misallocation and Manufacturing TFP in Bolivia during the Market Liberalization Period." The B.E. Journal of Macroeconomics, 12(1), 1-45.

Martin, Christopher (1993). "Price adjustment and market structure." Economics Letters, 41(2), 139-143.

Midrigan, Virgiliu and Daniel Xu (2014). "Finance and Misallocation: Evidence from Plant-level data." American Economic Review, 104(2), 422-458.

Moll, Benjamin (2014). "Productivity Losses from financial frictions: Can selffinancing undo capital misallocation?" American Economic Review, 104(10), 3186-3221.

Oaxaca, R. (1973). "Male-Female wage differentials in Urban Labor Markets." International Economic Review, 14(3), 693-709.

Peters, Michael (2013). "Heterogeneous mark-ups, growth and endogenous misallocation." mimeo, London School of Economics.

Restuccia, Diego and Richard Rogerson (2008). "Policy Distortions and Aggregate Productivity with Heterogeneous establishments." Review of Economic Dynamics, 11, 707-720.

Song, Zheng and Guiying Wu (2013). "A structural estimation on capital market distortions in Chinese Manufacturing." Economic Growth Centre Working Paper Series 1306, Nanyang Technological University, School of Humanities and Social Sciences, Economic Growth Centre.

Syverson, Chad (2004a). "Market structure and productivity: A concrete example." Journal of Political Economy, 112(6), 1181-1222.

Syverson, Chad (2004b). "Product substitutability and productivity dispersin." The Review of Economics and Statistics, 86(2), 534-550.

Vollrath, Dietrich (2015). "There is more to life than manufacturing." The growth economics blog, https://growthecon.wordpress.com/.

Ziebarth, Nicolas (2013). "Are China and India Backwards? Evidence from the 19th Century U.S. Census of Manufactures." Review of Economic Dynamics, 16(1), 86-99. 


\section{Appendix : Misallocation under alternative assumptions}

In this Appendix we investigate how changes in assumptions about the model impact the estimates for misallocation in the manufacturing and service sectors. In order to take the model to the data it is necessary to choose a value for the elasticity of substitution parameter $(\sigma)$, decide how to treat outliers, and choose the group of firms included in the analysis. Although it is already known that these assumptions will impact the estimated level of misallocation (see Hsieh and Klenow (2009) or Dias et al. (2016)), our interest is knowing whether the effect is homogeneous across industries and thus whether they significantly affect the misallocation differences between the manufacturing and service sectors.

As is common in the literature (see, for instance, Hsieh and Klenow (2009), Dias et al. (2016), Gopinath et al. (2015)), we use the wage bill paid by the firm (total labor costs) to measure labor input. Implicitly, we are assuming that wages per worker adjust for firm differences in hours worked per worker and worker skills. For the rental price of capital, we define an industry specific price equal to the industry depreciation rate plus a 5 percent real interest rate, so that $R_{s}=\delta_{s}+0.05$. For the intermediate inputs, we make a similar assumption as in the case of the labor input, and assume that the price of intermediate products, $Z_{s}$, is equal to 1 , so that the expenditure on intermediate inputs reflects not only the amount of inputs but also their quality. ${ }^{30}$

In line with other studies (see, for instance, Hsieh and Klenow (2009), Ziebarth (2013) and Dias et al. (2016)), we define a baseline by making the following set of assumptions: i) the elasticity of substitution, $\sigma$, equal to 3 ; ii) trimming the top and bottom 1.0 percent tails of scaled TFPR and TFP distributions across industries; ${ }^{31}$ iii) inclusion of all firms in the retained industries. ${ }^{32}$

30. Note that the values of $W_{s}, R_{s}$ and $Z_{s}$ affect the corresponding average wedges, but not the relative comparison between firms in a given industry. In other words, the choices of $W_{s}, R_{s}$ and $Z_{s}$ affect the estimates of the wedges (capital, labor, and output wedges), but not the efficiency gains calculated in this paper. Note also that to compute efficiency gains we only need to compute $T F P R_{s i}, T F P Q_{s i}\left(\right.$ or $\left.A_{s i}\right)$ and $T F P R_{s i}^{*}$, and that factor prices that are common to all firms in an industry cancel out.

31. That is, the distributions of $\ln \left(T F P R_{s i} / T F P R_{s}^{*}\right)$ and $\ln \left(A_{s i} M_{s}^{\frac{1}{\sigma-1}} / T F P_{s}^{*}\right)$ where $T F P_{s}^{*}$ is the industry efficient TFP defined in Section 2. More specifically, we pool all industries and omit the top and bottom 1 percent of firms in each of the pools to eliminate outliers and to control for possible measurement error. We then recalculate the relevant industry level aggregates such as $L_{s}, K_{s}, Q_{s}, P_{s} Y_{s}, T F P R_{s}^{*}$ and $T F P_{s}^{*}$.

32. In order to avoid computing misallocation with a very small number of firms, we drop industries that are left with less than 10 firms after the trimming. This condition is imposed in all variants considered in Table A1 below, to ensure comparability. After excluding industries with less than 10 firms, we are left with 162 different industries for 2008 ( 7 for agriculture, 80 for manufacturing and 75 for services) and 163 industries for 2010 ( 8 for agriculture, 79 for manufacturing and 76 for services). 
Next, we change assumptions i), ii) and iii) to gauge the impact each one and altogether have on the estimated efficiency gains and, more importantly, on the difference of misallocation between the service and manufacturing sectors. Specifically, we will investigate the implications of changing $\sigma$ and the level of trimming, as well as excluding smaller firms.

\begin{tabular}{lcccccccc}
\hline & \multicolumn{4}{c}{2008} & \multicolumn{4}{c}{2010} \\
\hline Assumptions & Total & $\mathrm{M}$ & $\mathrm{S}$ & $\mathrm{S}-\mathrm{M}$ & Total & $\mathrm{M}$ & $\mathrm{S}$ & $\mathrm{S}-\mathrm{M}$ \\
\hline 1) Baseline model & 43.36 & 16.02 & 59.19 & 43.18 & 49.33 & 16.81 & 66.46 & 49.65 \\
2) $\sigma=4.5$ & 63.48 & 19.93 & 90.65 & 70.72 & 71.55 & 20.33 & 100.84 & 80.51 \\
3) Trimming=2.5\% & 36.35 & 16.36 & 47.43 & 31.07 & 40.00 & 17.12 & 51.42 & 34.30 \\
4) Employment $>10$ & 28.31 & 12.92 & 38.33 & 25.41 & 31.37 & 13.43 & 41.68 & 28.25 \\
5) $=2)+3)$ & 48.98 & 19.73 & 66.01 & 46.29 & 53.33 & 19.61 & 71.09 & 51.49 \\
6) $=2)+4)$ & 34.97 & 15.13 & 48.18 & 33.05 & 38.85 & 15.71 & 52.52 & 36.82 \\
7)=3)+4) & 23.56 & 12.08 & 30.88 & 18.80 & 26.05 & 12.50 & 33.65 & 21.15 \\
8) Final model & 28.46 & 14.15 & 37.66 & 23.51 & 31.28 & 14.43 & 40.82 & 26.39 \\
\hline
\end{tabular}

Note: Efficiency gains in the baseline model are computed taking all the firms in the dataset, assuming $\sigma=3.0$ and trimming 1 percent tails of $\log \left(T F P R_{s i} / T F P R_{s}^{*}\right)$ and $\log \left(A_{s i} M^{\frac{1}{\sigma-1}} / T F P_{s}^{*}\right)$. M stands for manufacturing and $\mathrm{S}$ for services. $\mathrm{S}-\mathrm{M}$ is the difference between the service and the manufacturing sectors. The total also includes firms from agriculture.

TABlE A1. Efficiency gains under alternative assumptions

The efficiency gains for 2008 and 2010, obtained under the baseline assumptions, are recorded in Table A1. We can see from the first row that, if distortions in the economy were eliminated (by equalizing TFPR across firms in each industry and keeping industry level factor demand constant), the grossoutput efficiency gains (or TFP gains) for the whole economy would be around 43 percent in 2008 and 49 percent in 2010 (this figure also includes firms from agriculture). Efficiency gains are also clearly higher in the service sector (around 59 percent in 2008 and 66 percent in 2010) than in the manufacturing sector (around 16 and 17 percent in 2008 and 2010, respectively). Thus, the service sector emerges as far more inefficient than the manufacturing sector, in line with the results in Dias et al. (2016). However, one question that may arise here is whether the documented difference in misallocation between the two sectors can be explained by one or more of the assumptions that underly the baseline results. We therefore now consider the implications of alternative assumptions to the baseline.

\section{Elasticity of substitution}

It is well known that the assumed value of $\sigma$ has important implications for the estimated efficiency gains in the context of the Hsieh and Klenow (2009) model (see, for instance, Hsieh and Klenow (2009), Dias et al. (2016)), and that higher values of $\sigma$ are associated with higher levels of efficiency gains. In the absence of country specific estimates, the empirical literature usually assumes $\sigma=3$ as a way of computing a conservative estimate for the importance of 
misallocation. However, the empirical estimates for industry markups usually suggest higher values for $\sigma$, both in the Eurozone and the U.S. (see, for instance, Christopoulou and Vermeulen (2012)). The estimates available for Portugal for the 2004-2009 period (see Amador and Soares (2013)) are also on average above 3. In particular, the 3-digit industry level estimates for the markups, under the assumption of imperfect labor markets, imply an (nonweighted) average of $\sigma=4.5$ for the Portuguese economy. Moreover, there is not a significant difference between the average estimates for manufacturing and service sectors. Therefore, in what follows, we use $\sigma=4.5$, which is a more realistic number for the Portuguese economy. From Table A1 (second row), we see that the estimated efficiency gains increase vis-à-vis the baseline in the two sectors. Moreover, the increase in the service sector is significantly higher implying that the difference between the two sectors increases from around 43 percentage points (p.p.) to around 71 p.p. in 2008, and from around 50 p.p. to around 81 p.p. in 2010.

\section{Treatment of outliers}

The presence of outliers also has strong implications for the empirical estimates of efficiency gains. For example, if a firm mistakenly reports very low input factors, it will generate very large numbers for TFP and TFPR, giving rise to spurious misallocation. ${ }^{33}$ One way to deal with this problem is to trim the distributions of scaled TFP and scaled TFPR. ${ }^{34}$ Of course, the choice of the trimming is largely ad-hoc and it has implications for the results, especially in cases of large measurement errors. The way changes in the trimming affects the difference of efficiency gains between the service and the manufacturing sectors will depend on how outliers are distributed across the two sectors.

Table A1 (third row) also reports the estimates for TFP gains when we trim 2.5 percent on each tail of the scaled TFP and TFPR distributions. As could be expected the estimated TFP gains for the whole economy are lower. For instance, for 2008, efficiency gains drop from 63 to 49 percent if we use $\sigma=4.5$ (rows 2 and 5), or from 43 to 36 percent if we use $\sigma=3$ (rows 1 and 3). More interestingly, however, is that we see estimated efficiency gains decrease in the service sector, but remain basically unchanged in the manufacturing sector, so that the difference between the two sectors is reduced from 71 to 46 percent in the model with $\sigma=4.5$ (or from 43 to 31 percent in the model with $\sigma=3$ ), thanks only to changes in the service sector. This result shows that a significant

33. Note that, in the model, both TFP and TFPR are computed using the production function, i.e., $T F P_{s i}=A_{s i}=Y_{s i} /\left(K_{s i}^{\alpha_{s}} H_{s i}^{\beta_{s}} Q_{s i}^{1-\alpha_{s}-\beta_{s}}\right)$ and $T F P R_{s i}=P_{s i} A_{s i}=$ $P_{s i} Y_{s i} /\left(K_{s i}^{\alpha_{s}} H_{s i}^{\beta_{s}} Q_{s i}^{1-\alpha_{s}-\beta_{s}}\right)$. Thus, reporting mistakes involving the inputs or gross output (sales) translate into abnormal TFP and TFPR figures, which directly affect estimates of efficiency gains.

34. Another one could be to compute winsorized efficiency gains at a given percent level. 
part of the baseline difference between the two sectors is due to outliers that are concentrated in the service sector.

Minimum firm size

Another important issue is the minimum firm size to consider in the exercise. The results in Dias et al. (2016) suggest that an important part of the misallocation problems due to distortions in the Portuguese economy is concentrated in the micro and small service sector firms. Technically, it is possible to compute the efficiency gains stemming from labor distortions for firms with one or more employees. However, it is unclear whether micro or very small firms should be included in the computation of efficiency gains. In fact, the reallocation gains in some of these firms may be somewhat overestimated, either because the model does not allow for indivisibilities in the input factors (labor force or capital stock), which mainly affect micro and small firms, or because some of these units (young firms) might be growing at a faster pace, as they are in the process of converging to their optimal size. Furthermore, because tax collection enforcement focus more on large firms, micro and small firms are more likely to exhibit noncompliance with taxes by misreporting some relevant items like sales or gross output, also implying higher distortions.

Table A2 reports the estimated efficiency gains corresponding to different restrictions on firm size, as measured by the number of employees, under the baseline assumptions. In particular, we compute the efficiency gains within micro and small firms vis-à-vis efficiency gains within larger firms, for different cut-offs of employment. A very important conclusion is that efficiency gains are much higher within micro and small firms, than within larger firms. For instance, efficiency gains for the whole economy in 2008, within firms with 5 or less employees, are around 87 percent, compared to 32 percent within firms with more than 5 employees (43 percent if we take the firms altogether). If we restrict the sample to firms with between 6 and 10 employees, efficiency gains are about 45 percent, i.e., significantly lower than within firms with 1 to 5 . Nevertheless, this is significantly higher than the efficiency gains within firms with more than 10 employees (28 percent). As the size of firms (employment cut-offs) increases, the difference in the efficiency gains between small and big firms shrinks. In particular, efficiency gains for firms with employment between 10 and 15 employees are close to the efficiency gains for firms with more than 15 employees, especially in the service sector.

Overall, the results in Table A2 show that heterogeneity (efficiency gains) within small firms is higher than heterogeneity between small and large firms. This is an interesting result on its own. Indivisibilities, faster growth or financial constraints faced by small firms could explain heterogeneity between small firms and large firms, and thus explain higher efficiency gains in industries with a higher proportion of small firms. However, these factors cannot explain the high heterogeneity uncovered within small firms. We believe that misreporting 


\begin{tabular}{lcccccc}
\hline & \multicolumn{3}{c}{2008} & & & 2010 \\
\hline & Total & Manuf & Serv & Total & Manuf & Serv \\
\hline All firms & 43.36 & 16.02 & 59.19 & 49.33 & 16.81 & 66.46 \\
\hline Empl $<=5$ & 87.04 & 34.95 & 95.10 & 89.74 & 36.91 & 97.89 \\
Empl $>5$ & 31.54 & 13.74 & 42.39 & 34.21 & 14.59 & 44.83 \\
\hline $5<$ Empl $<=10$ & 44.54 & 22.03 & 49.76 & 48.50 & 23.46 & 53.88 \\
Empl $<=10$ & 71.15 & 28.03 & 79.34 & 77.00 & 29.77 & 86.14 \\
Empl $>10$ & 28.31 & 12.92 & 38.33 & 31.37 & 13.43 & 41.68 \\
\hline $10<$ Empl $<=15$ & 34.91 & 19.57 & 39.91 & 42.96 & 20.71 & 50.17 \\
Empl $<=15$ & 64.74 & 25.63 & 73.43 & 71.55 & 27.32 & 81.44 \\
Empl $>15$ & 26.79 & 12.47 & 36.44 & 29.66 & 12.73 & 39.72 \\
\hline $15<$ Empl $<=20$ & 31.78 & 14.83 & 39.77 & 35.22 & 17.76 & 42.03 \\
Empl $<=20$ & 62.05 & 24.98 & 71.64 & 67.14 & 25.64 & 77.45 \\
Empl $>20$ & 25.89 & 12.01 & 35.42 & 29.55 & 13.96 & 38.92 \\
\hline
\end{tabular}

Note:Baseline assumptions: $\sigma=3.0$ and trimming 1 percent tails of $\log \left(T F P R_{s i} / T F P R_{s}^{*}\right)$ and $\log \left(A_{s i} M^{\frac{1}{\sigma-1}} / T F P_{s}^{*}\right)$.

TABLE A2. Efficiency gains for different employment cut-offs (baseline assumptions)

of some relevant items, like sales or gross output might be an explanation for some of the results in Table A2.

For the purpose of the present exercise, we restrict the analysis to firms with more than 10 employees. The chosen cut-off is somewhat ad-hoc but we believe that given the importance of small and medium-sized firms in the Portuguese economy this solution strikes a balance between the need to reduce the importance of spurious misallocation and the representativeness of the final sample. By dropping firms with 10 or less employees, the number of firms in the dataset is reduced from 236,022 to 41,123 in 2008 and from 230,157 to 38,675 in 2010. Despite representing around 83 percent of the total number of firms, firms with 10 or less employees account only for 16.8 percent of total gross output and 25.4 percent of total employment in 2008 (the figures for 2010 are similar). From Table A1, we see that if we drop firms with 10 or fewer employees from the dataset, the efficiency gains for the whole economy are reduced from around 43 to about 28 percent (row 4), and the difference between the two sectors is reduced from 43 p.p. to 25 p.p. in 2008 and from 50 p.p. to 28 p.p. in 2010.

Finally, if we consider the three changes to the baseline altogether $(\sigma=4.5$, trimming $=2.5$ and employment $>10$ ), we get what we denote as the "final model" assumptions. Under this set of assumptions, the efficiency gains for the whole economy drop to about 28 percent in 2008 , and to about 31 percent in 2010 (see last row in Table A1). In turn, the differences between the service and the manufacturing sectors drop to about 24 p.p. in 2008 and to about 26 p.p. in 2010 .

Summing up, the evidence in this Appendix shows that the existence of a significant difference in allocative efficiency between the manufacturing and service sectors does not rest on the possible assumptions about the elasticity of 
substitution parameter $(\sigma)$, the way outliers are dealt with or the type of firms included in the analysis. ${ }^{35}$

35. It has been claimed (see, for instance, Vollrath (2015)) that, for historical reasons, data collection and classification is skewed towards manufacturing in the sense that it provides a much more detailed industry classification in manufacturing than in the service sector. In order to understand how the estimates of the difference of efficiency gains between the two sectors depend on the level of industry classification, we computed the efficiency gains using a 5-digit industry definition. Compared to the 3 -digit results in Table A1, we conclude that global efficiency gains decrease, but not by much, which means that misallocation is not a spurious outcome of aggregation. Efficiency gains stay virtually unchanged in the manufacturing sector, but decrease somewhat in the service sector, reflecting the impact of a higher increase in disaggregation in this sector. Nevertheless, the difference of efficiency gains between the two sectors remains very high. For instance, in the "final model" case of Table A1, the difference in the 5-digit case is 17.64 p.p., in 2008 (compared to 23.51 p.p. in the 3 -digit case), and 21.67 p.p. in 2010 (compared to 26.39 p.p. in the 3 -digit case). Thus, in the paper we focus on the 3-digit case, not only because it does not make a significant difference in quantitative terms, but also because in the 5-digit case, industries have, on average, a smaller number of firms, implying more volatile estimates of industry-level efficiency gains and of the regressors used in the analysis. 


\section{WORKING PAPERS}

\section{3}

01|13 Macroeconomic forecasting using lowfrequency filters

João Valle e Azevedo | Ana Pereira

02|13 Everything you always wanted to know about sex discrimination

Ana Rute Cardoso | Paulo Guimarães | Pedro Portugal

03|13 Is there a role for domestic demand pressure on export performance?

Paulo Soares Esteves | António Rua

04|13 Ageing and fiscal sustainability in a small euro area economy

Gabriela Castro | José R. Maria | Ricardo Mourinho Félix | Cláudia Rodrigues Braz

05|13 Mind the gap! The relative wages of immigrants in the Portuguese labour market Sónia Cabral | Cláudia Duarte

06|13 Foreign direct investment and institutional reform: Evidence and an application to Portugal

Paulo Júlio | Ricardo Pinheiro-Alves | José Tavares

07|13 Monetary policy shocks: We got news! Sandra Gomes | Nikolay Iskrev | Caterina Mendicino

08|13 Competition in the Portuguese Economy: Estimated price-cost margins under imperfect labour markets

João Amador | Ana Cristina Soares

09|13 The sources of wage variation: a threeway high-dimensional fixed effects regression model

Sonia Torres | Pedro Portugal | John T. Addison | Paulo Guimarães
10|13 The output effects of (non-separable) government consumption at the zero lower bound

Valerio Ercolani | João Valle e Azevedo

11|13 Fiscal multipliers in a small euro area economy: How big can they get in crisis times?

Gabriela Castro | Ricardo M. Felix | Paulo Julio | Jose R. Maria

12|13 Survey evidence on price and wage rigidities in Portugal

Fernando Martins

13|13 Characterizing economic growth paths based on new structural change tests Nuno Sobreira | Luis C. Nunes | Paulo M. M. Rodrigues

14|13 Catastrophic job destruction Anabela Carneiro | Pedro Portugal | José Varejão

$15 \mid 13$ Output effects of a measure of tax shocks based on changes in legislation for Portugal

Manuel Coutinho Pereira | Lara Wemans

16|13 Inside PESSOA - A detailed description of the model

Vanda Almeida | Gabriela Castro | Ricardo M. Félix | Paulo Júlio | José R. Maria

17|13 Macroprudential regulation and macroeconomic activity

Sudipto Karmakar

18|13 Bank capital and lending: An analysis of commercial banks in the United States Sudipto Karmakar | Junghwan Mok 


\section{4}

1|14 Autoregressive augmentation of MIDAS regressions

Cláudia Duarte

2|14 The risk-taking channel of monetary policy - exploring all avenues

Diana Bonfim | Carla Soares

3|14 Global value chains: Surveying drivers, measures and impacts

João Amador | Sónia Cabral

4|14 Has US household deleveraging ended? a model-based estimate of equilibrium debt

Bruno Albuquerque | Ursel Baumann | Georgi Krustev

5|14 The weather effect: estimating the effect of voter turnout on electoral outcomes in italy

Alessandro Sforza

6|14 Persistence in the banking industry: fractional integration and breaks in memory Uwe Hassler | Paulo M.M. Rodrigues | Antonio Rubia

7|14 Financial integration and the great leveraging Daniel Carvalho

8|14 Euro area structural reforms in times of a global crisis

Sandra Gomes

9|14 Labour demand research: towards a better match between better theory and better data

John T. Addison | Pedro Portugal | José Varejão
10|14 Capital inflows and euro area long-term interest rates

Daniel Carvalho | Michael Fidora

11|14 Misallocation and productivity in the lead up to the Eurozone crisis

Daniel A. Dias | Carlos Robalo Marquesz | Christine Richmond

12|14 Global value chains: a view from the euro area

João Amador | Rita Cappariello | Robert Stehrer

13|14 A dynamic quantitative macroeconomic model of bank runs

Elena Mattana | Ettore Panetti

14|14 Fiscal devaluation in the euro area: a model-based analysis

S. Gomes | P. Jacquinot | M. Pisani

15|14 Exports and domestic demand pressure: a dynamic panel data model for the euro area countries

Elena Bobeica | Paulo Soares Esteves | António Rua | Karsten Staehr

16|14 Real-time nowcasting the US output gap: singular spectrum analysis at work Miguel de Carvalho | António Rua 
1|15 Unpleasant debt dynamics: can fiscal consolidations raise debt ratios?

Gabriela Castro | Ricardo M. Félix | Paulo Júlio | José R. Maria

2|15 Macroeconomic forecasting starting from survey nowcasts

João Valle e Azevedo | Inês Gonçalves

3|15 Capital regulation in a macroeconomic model with three layers of default

Laurent Clerc | Alexis Derviz | Caterina Mendicino | Stephane Moyen | Kalin Nikolov | Livio Stracca | Javier Suarez | Alexandros P. Vardoulakis

4|15 Expectation-driven cycles: time-varying effects

Antonello D'Agostino | Caterina Mendicino

5|15 Seriously strengthening the tax-benefit link

Pedro Portugal | Pedro S. Raposo

6|15 Unions and collective bargaining in the wake of the great recession

John T. Addison | Pedro Portugal | Hugo Vilares

7|15 Covariate-augmented unit root tests with mixed-frequency data

Cláudia Duarte

8|15 Financial fragmentation shocks

Gabriela Castro | José R. Maria | Paulo úlio | Ricardo M. Félix

9|15 Central bank interventions, demand for collateral, and sovereign borrowing cost Luís Fonseca | Matteo Crosignani | Miguel Faria-e-Castro
10|15 Income smoothing mechanisms after labor market transitions

Nuno Alves | Carlos Martins

11|15 Decomposing the wage losses of displaced workers: the role of the reallocation of workers into firms and job titles Anabela Carneiro | Pedro Raposo | Pedro Portugal

12|15 Sources of the union wage gap: results from high-dimensional fixed effects regression models

John T. Addison | Pedro Portugal | Hugo Vilares

13|15 Assessing european firms' exports and productivity distributions: the compnet trade module Antoine Berthou | Emmanuel Dhyne | Matteo Bugamelli | Ana-Maria Cazacu | Calin-Vlad Demian | Peter Harasztosi | Tibor Lalinsky | Jaanika Meriküll | Filippo Oropallo | Ana Cristina Soares

14|15 A new regression-based tail index estimator: an application to exchange rates

João Nicolau | Paulo M. M. Rodrigues

15|15 The effect of bank shocks on firm-level and aggregate investment João Amador | Arne J. Nagengast

16|15 Networks of value added trade João Amador | Sónia Cabral

17|15 House prices: bubbles, exuberance or something else? Evidence from euro area countries Rita Fradique Lourenço | Paulo M. M. Rodrigues 


\section{6}

1|16 A mixed frequency approach to forecast private consumption with ATM/POS data

Cláudia Duarte | Paulo M. M. Rodrigues | António Rua

2|16 Monetary developments and expansionary fiscal consolidations: evidence from the EMU

António Afonso | Luís Martins

3|16 Output and unemployment, Portugal, 2008-2012

José R. Maria

4|16 Productivity and organization in portuguese firms

Lorenzo Caliendo | Luca David Opromolla | Giordano Mion | Esteban Rossi-Hansberg

5|16 Residual-augmented IVX predictive regression

Matei Demetrescu | Paulo M. M. Rodrigues

6|16 Understanding the public sector pay gap Maria M. Campos | Evangelia Papapetrou | Domenico Depalo Javier J. Pérez | Roberto Ramos

7|16 Sorry, we're closed: loan conditions when bank branches close and firms transfer to another bank

Diana Bonfim | Gil Nogueira | Steven Ongena

$8 \mid 16$ The effect of quantitative easing on lending conditions

Laura Blattner | Luísa Farinha | Gil Nogueira
9|16 Market integration and the persistence of electricity prices

João Pedro Pereira | Vasco Pesquita | Paulo M. M. Rodrigues | António Rua

10|16 EAGLE-FLI | A macroeconomic model of banking and financial interdependence in the euro area

N. Bokan | A. Gerali | S. Gomes | P. Jacquinot M. Pisani

11|16 Temporary contracts' transitions: the role of training and institutions

Sara Serra

12|16 A wavelet-based multivariate multiscale approach for forecasting António Rua

13|16 Forecasting banking crises with dynamic panel probit models António Antunes | Diana Bonfim | Nuno Monteiro | Paulo M. M. Rodrigues

14|16 A tale of two sectors: why is misallocation higher in services than in manufacturing? Daniel A. Dias | Carlos Robalo Marques | Christine Richmond 


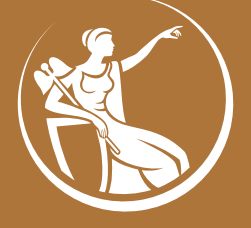

